\title{
Planning and Operating a Renewable-Dominated European Power System under Uncertainty
}

\author{
Ruth Domínguez ${ }^{1}$ \\ Miguel Carrión ${ }^{1}$ \\ Giorgia Oggioni ${ }^{3}$ \\ ${ }^{1}$ University of Castilla-La Mancha, Department of Electrical Engineering, Toledo, Spain. \\ ${ }^{2}$ University of Brescia, Department of Economics and Management, Brescia, Italy.
}

\begin{abstract}
In this paper we study the European power system for 2050 from both the expansion and the operation perspectives. First, the generating and storage capacity to be built is decided by solving a multi-stage investment model taking into account the uncertainty related to the investment costs and the demand growth. Stochastic programming is used to represent this decision-making problem under uncertainty. Second, the daily operation of the resulting European power system is analyzed. A two-stage stochastic-programming problem is proposed to model the day-ahead energy and reserve markets in the first stage, and the real-time operation in the second stage. At this level, the uncertainty of the hourly available wind and solar power and the demand level is considered. The numerical results indicate that an European power system mainly based on solar and onshore wind power is possible at a reasonable cost if storage units are also installed. The total new generating capacity to be built up to 2050 will be around $881 \mathrm{GW}$, which leads to an investment cost of at least 1622 billion euros. The possibility of wind, solar and storage units to provide a certain reserve capacity allows to reduce the participation of thermal units. Therefore, a 77\% reduction in the $\mathrm{CO}_{2}$ emissions respect to 1990 may be achieved in 2050. Finally, unserved demand is found in few countries only in 75 hours of the year, while the average daily energy prices are stable and comparatively low among the countries.
\end{abstract}

Keywords - Energy and reserve, intermittent production, investment, operation, stochastic programming.

\section{Introduction}

Sustainability is a concept that has been developed through time following different directions and across multiple areas. The first and mostly known aspect of sustainability is connected to the dramatic problem of the climate change. The energy sector is key to limit climate change as indicated in the Paris Agreement ${ }^{1}$, which is considered fundamental for the achievement of a low-carbon economy. This entails the process of disrupting carbon lock-in and removing fossil fuels from our energy and economic systems. The European efforts toward a low-carbon economy started in 2005 with the introduction of the European Union-Emissions Trading System (EU-ETS). The EU-ETS is the first and the largest cap-and-trade system applied at worldwide level and it has been implemented to abate European $\mathrm{CO}_{2}$ emissions. It helped Europe to fulfill its Kyoto Protocol commitments and is the baseline for the so-called 20-20-20 targets, which impose a $\mathrm{CO}_{2}$ emissions cut by $20 \%$, a Renewable Energy Sources (RES) penetration increase by 20\%, and an improvement of energy efficiency by $20 \%$ compared to 1990 levels within $2020^{2}$. The accomplishment of these targets is needed to reach the full decarbonization of energy systems as stated in the Energy Roadmap 2050, which establishes a reduction of 80\%-95\% greenhouse gas (GHG) emissions compared to the 1990 levels by 2050 (see European Commission, 2011). This ambitious GHG reduction benchmark cannot be reached without a full decarbonization of the power sector. Different decarbonization pathways have been proposed to attain a more sustainable, flexible, secure, and competitive energy systems in 2050. These pathways are represented by investments in RES-based and gas-fired power plants, in the electrification of the transport sector, and in efficient technologies such as those based on "carbon capture and storage" of $\mathrm{CO}_{2}$ emissions. The strategic role played by wind and solar power in the European decarbonization process has been also highlighted by the "Winter Package", that is a package of eight measures issued on November 30th, 2016 by the European Commission to facilitate the transition to a "clean energy economy" and to reform the design and the operation of the European electricity market ${ }^{3}$. In particular, it has fixed two new intermediate targets to be reached by 2030: a binding renewable energy target of at least 32\% and an energy efficiency target of at least 32.5\%, with a possible revision in 2023.

\footnotetext{
${ }^{1}$ See https://unfccc.int/sites/default/files/english_paris_agreement.pdf

${ }^{2}$ See https://ec.europa.eu/clima/policies/strategies/2020_en

${ }^{3}$ See https://ec. europa.eu/energy/en/topics/energy-strategy-and-energy-union/clean-energy-all-europeans
} 
Even though the electricity produced by wind and solar power plants is clean, its penetration in energy systems is not easy because of the variability and the intermittence that characterize these natural sources. This implies discrepancies between RES electricity forecasts in day ahead and the actual RES generation in real time when the electricity is delivered. Thus, real time electricity injections in the grid may dramatically differ from those forecasted, leading to serious planning and operating challenges that can be partially overcome by the utilization of storage units. On the other side, concentrating solar power and offshore wind power plants are less intermittent than the PV solar and onshore wind units, but they are less developed and, consequently, their implementation is more uncertain.

The achievement of the environmental targets is also influenced by the design of the European electricity market that is based on the separation of the energy and the ancillary services markets. More precisely, Power Exchanges (PXs) clear the day-ahead electricity market, taking into account a zonal representation of the network, and Transmission System Operators (TSOs) procure reserve capacity, manage network congestion, and solve the imbalances that occur in real time after the Intraday Market (IM) enables "Balancing Responsible Parties" to manage some of these (im)balances. The restructuring of the European electricity market started at the end of the '90s thanks to Directive 96/92/EC that was then substituted by Directive 2003/54/EC. The deregulation process was introduced to guarantee reliable energy supplies at reasonable prices and to create competitive and integrated EU gas and electricity markets. Despite some significant progresses, competition was slow to take off, markets remained largely national and highly concentrated, with relatively little cross-border trade. That is why the European Commission launched the Third Legislative Package in 2009 to overcome all these problems that are still under discussion ${ }^{4}$. In particular, the Third Energy Package and the related ENTSO-E Network Codes ${ }^{5}$ for electricity aim at creating an Internal Energy Market (IEM) through the coordination of the day-ahead energy markets, the reserve procurement, the congestion management and the balancing markets. The first step toward this market integration has been represented by the Price Coupling of Regions (PCRs), that is an initiative of seven European PXs to develop a single pricing and cross-border capacity allocation mechanisms across Europe on a day-ahead basis.

Considering this complex framework, in this paper, we focus on the planning and the operation of a European renewabledominated power system where both environmental policies and market design issues are analyzed. In particular, we propose a fully integrated European electricity market for 2050 where energy and reserve capacity are simultaneously dispatched in the day-ahead market. The underlying assumption of this modeling approach is that, by 2050 the transformation of the European electricity system as required by the Network Codes and the Winter Package will lead to a market design very similar to that applied in the US, where an Independent System Operator manages both the energy and ancillary services markets and simultaneously co-optimizes energy and reserves. In our analysis, we also consider how the European decarbonization targets can affect the investment planning and the operation of the whole power system. In doing this, we consider the uncertainty involved in the decision-making processes in two ways: first, in the planning process the investment decisions are affected by the evolution of the demand growth and technology costs along the planning horizon; and second, the system is operated considering the randomness associated to RES power production and the consumption. The numerical analysis is based on realistic data of 24 European countries and is conducted taking into account the cross-border limitations among Member States.

Many modeling approaches have been proposed to analyze the feasibility of a renewable-dominated European Power System (see Rasmussen et al., 2012; Brancucci Martínez-Anido et al., 2013; Connolly et al., 2016; Gils et al., 2017; Eriksen et al. 2017; Schlachtberger et al., 2017; Domínguez et al., 2017). Table 1 summarizes the most relevant features of these models. Observe that none of the works analyzed takes into account the uncertainty of the future demand or the investment costs when deciding the generating capacity investments. Additionally, none of these works considers the uncertainty associated with the operation of a power system with a high penetration of generating units with intermittent and uncertain power output. Finally, most of the analyzed models consider that investment decisions are made in a single shot, without modeling the progressive decommissioning of existing generating units and the future evolution of the uncertain parameters.

Table 1: Previous works analyzing the future European Power System

\begin{tabular}{|c|c|c|c|c|c|c|}
\hline Work & Target year & Number of nodes & $\begin{array}{c}\text { Investment } \\
\text { decisions }\end{array}$ & $\begin{array}{c}\text { Number of } \\
\text { decision stages }\end{array}$ & $\begin{array}{c}\text { Uncertainty } \\
\text { in investment }\end{array}$ & $\begin{array}{l}\text { Uncertainty } \\
\text { in operation }\end{array}$ \\
\hline Rasmussen et al. (2012) & Not specified & 1 & Yes & 1 & No & No \\
\hline Brancucci Martínez-Anido et al. (2013) & 2025 & 32 & No & - & - & No \\
\hline Connolly et al. (2016) & 2050 & 1 & No & - & - & No \\
\hline Gils et al. (2017) & Not specified & 15 & Yes & 1 & No & No \\
\hline Eriksen et al. (2017) & Not specified & 30 & Yes & 1 & No & No \\
\hline Schlachtberger et al. (2017) & Present $\left(95 \% \mathrm{CO}_{2}\right.$ reduction $)$ & 30 & Yes & 1 & No & No \\
\hline Domínguez et al. (2017) & 2050 & 24 & No & - & - & Yes \\
\hline Schlachtberger et al. (2018) & Present $\left(95 \% \mathrm{CO}_{2}\right.$ reduction) & 30 & Yes & 1 & No & No \\
\hline Brown et al. (2018) & Present (95\% $\mathrm{CO}_{2}$ reduction)) & 30 & Yes & 1 & No & No \\
\hline
\end{tabular}

This paper seeks to overcome these limitations proposing a multi-stage capacity investment model for the European Power System considering explicitly the long-term uncertainty pertaining to future investment costs of generating and storage tech-

\footnotetext{
${ }^{4}$ See https://ec. europa.eu/energy/en/topics/markets-and-consumers/market-legislation
}

${ }^{5}$ See https://electricity.network-codes.eu/network_codes/ 
nologies and the annual demand growth. These uncertain parameters are modeled using a set of scenarios that are generated using well-founded estimations obtained from technical reports (see IEA, 2016 and European Commission, 2015). The operation of the resulting power system is tested using a day-ahead market clearing procedure that allows to simultaneously dispatch the energy and reserve capacity markets considering the uncertainty of the next-day demand and the power availability of the intermittent units. The uncertainty associated with these parameters is modeled based on the day-ahead forecast errors that are available from the ENTSO-E transparency platform web page. ${ }^{6}$

Therefore, the objectives of this paper are: first, to determine the investment decisions to be made in the next years to attain the environmental goals established by the European Union for 2050; and second, to analyze the technical and economical performance of the resulting power system considering the uncertainty related to the intermittent renewable production and the demand. Consequently, the contributions of this paper are threefold:

- To propose a multi-stage investment model considering long-term uncertainties for deciding the capacity to be built of generating and storage technologies in the European power system towards 2050.

- To test the daily operation of the resulting European power system using a day-ahead market clearing procedure that cooptimizes simultaneously energy and reserve capacity procurement considering the uncertainty related to the intermittent renewable production.

- To derive technical and economical conclusions from the investment and operating points of view and, based on them, propose policy recommendations to attain the GHG emission goal while ensuring the technical and economical feasibility of the system.

The paper is structured as follows. In Section 2 the input data used to define the numerical study is included. Section 3 describes the proposed methodology used to characterize the investment and operation problems. The obtained results are shown and discussed in Section 4. Finally, Section 5 ends the paper providing the main conclusions obtained from this study. In the appendices the mathematical formulations of the proposed models are explained.

\section{Data}

This section includes the input data used to describe the considered European Power System.

\subsection{Common data}

Taking into account the power systems coupled through the Price Coupling of Regions (PCR) in 2016, ${ }^{7}$ we consider the following 24 countries: Austria (AT), Belgium (BE), Czech Republic (CZ), Denmark (DK), Estonia (EE), Finland (FI), France (FR), Germany (DE), Hungary (HU), Italy (IT), Latvia (LV), Lithuania (LT), Luxembourg (LU), the Netherlands (NL), Norway (NR), Poland (PL), Portugal (PT), Romania (RO), Slovakia (SK), Slovenia (SI), Spain (ES), Sweden (SE), Switzerland (CH), and the United Kingdom (UK). Due to its geographical position, Switzerland is also included in the network. Each country is represented by a bus. The buses are connected as depicted in Figure 1, with a total of 40 interconnections. In particular, we consider both the current and prospective interconnections according to the data available in the ENTSO-E platform. ${ }^{8}$

The generating technologies considered are: nuclear (Nucl), coal (Coal), combined cycle gas turbine (CCGT), hydroelectric with reservoir (HRes), run-of-river hydro (HRoR), onshore/offshore wind (Wons/Woff), solar photovoltaic (SoPV), concentrating solar power (SoTH) and biomass (Biom). For this study, we consider as reference year 2016. Table 2 provides the capacity built per technology by the end of 2016 according to the data available on the ENTSO-E transparency platform. ${ }^{9}$

Table 3 reports the costs and the ramping capacity of the considered technologies. The investment costs (second column) are defined according to the projections made by the International Energy Agency in IEA (2016).

\footnotetext{
${ }^{6}$ ENTSO-E transparency platform, 2018. Available at: https://transparency.entsoe.eu/

${ }^{7}$ See PCR Project Main features. Available at: https://www . epexspot.com/en/market-coupling/pcr

${ }^{8}$ See ENTSO-E, Europe's network development plan to 2025, 2030 and 2040. Available at: https://tyndp. entsoe. eu/

${ }^{9}$ ENTSO-E transparency platform, 2018. Available at: https://transparency.entsoe.eu/
} 


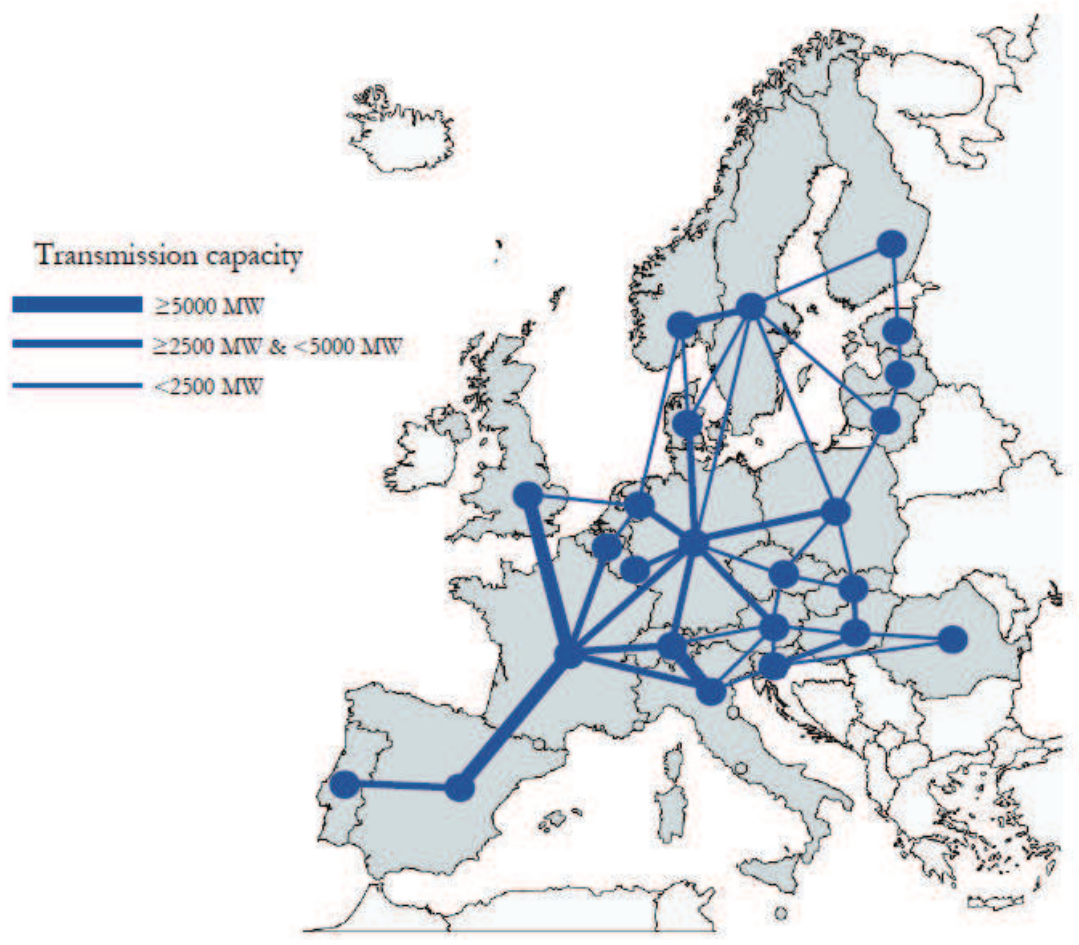

Figure 1: Transmission system

Table 2: Total capacity per technology and per country in the end of 2016 (GW)

\begin{tabular}{|c|c|c|c|c|c|c|c|c|c|c|c|c|}
\hline Country & Nucl & Coal & CCGT & HRes & HRoR & Wons & Woff & SoPV & SoTH & Biom & Total & $(\%)$ \\
\hline AT & 0.000 & 0.766 & 4.466 & 5.965 & 5.575 & 2.497 & 0.000 & 0.723 & 0.000 & 0.474 & 20.466 & 2.4 \\
\hline $\mathrm{BE}$ & 5.919 & 0.470 & 5.373 & 1.300 & 0.117 & 1.249 & 0.712 & 2.953 & 0.000 & 0.710 & 18.803 & 2.2 \\
\hline $\mathrm{CH}$ & 3.375 & 0.000 & 0.000 & 9.002 & 0.190 & 0.000 & 0.000 & 0.000 & 0.000 & 0.000 & 12.567 & 1.5 \\
\hline $\mathrm{CZ}$ & 4.040 & 9.914 & 1.226 & 1.820 & 0.650 & 0.277 & 0.000 & 2.067 & 0.000 & 0.350 & 20.344 & 2.4 \\
\hline DE & 10.952 & 50.758 & 26.694 & 9.227 & 3.749 & 39.937 & 3.256 & 38.994 & 0.000 & 6.609 & 190.176 & 22.2 \\
\hline DK & 0.000 & 4.847 & 2.941 & 0.000 & 0.009 & 3.574 & 1.271 & 0.601 & 0.000 & 0.197 & 13.440 & 1.6 \\
\hline EE & 0.000 & 0.086 & 0.119 & 0.000 & 0.008 & 0.375 & 0.000 & 0.001 & 0.000 & 0.077 & 0.666 & 0.1 \\
\hline ES & 7.572 & 10.467 & 30.295 & 19.076 & 1.156 & 22.772 & 0.000 & 4.200 & 2.300 & 0.705 & 98.543 & 11.5 \\
\hline FI & 2.782 & 4.416 & 1.482 & 0.500 & 3.112 & 1.082 & 0.000 & 0.000 & 0.000 & 1.534 & 14.908 & 1.7 \\
\hline FR & 63.130 & 2.930 & 6.121 & 8.204 & 10.326 & 10.505 & 0.010 & 6.100 & 0.000 & 1.248 & 108.574 & 12.7 \\
\hline $\mathrm{HU}$ & 1.887 & 1.007 & 4.124 & 0.028 & 0.029 & 0.328 & 0.000 & 0.029 & 0.000 & 0.246 & 7.678 & 0.9 \\
\hline IT & 0.000 & 7.152 & 29.923 & 11.290 & 10.482 & 8.739 & 0.000 & 4.768 & 0.000 & 1.610 & 73.964 & 8.6 \\
\hline LT & 0.000 & 0.000 & 1.719 & 0.900 & 0.128 & 0.366 & 0.000 & 0.069 & 0.000 & 0.065 & 3.247 & 0.4 \\
\hline LU & 0.000 & 0.000 & 1.103 & 0.000 & 1.537 & 0.055 & 0.000 & 0.000 & 0.000 & 0.102 & 2.797 & 0.3 \\
\hline LV & 0.000 & 0.000 & 1.103 & 0.000 & 1.537 & 0.055 & 0.000 & 0.000 & 0.000 & 0.102 & 2.797 & 0.3 \\
\hline NL & 0.486 & 5.658 & 19.914 & 0.000 & 0.038 & 3.284 & 0.357 & 1.429 & 0.000 & 0.398 & 31.564 & 3.7 \\
\hline NR & 0.000 & 0.000 & 1.412 & 26.910 & 1.352 & 0.873 & 0.050 & 0.000 & 0.000 & 0.000 & 30.597 & 3.6 \\
\hline PL & 0.000 & 27.120 & 1.302 & 1.926 & 0.395 & 5.494 & 0.000 & 0.077 & 0.000 & 0.435 & 36.749 & 4.3 \\
\hline PT & 0.000 & 1.756 & 4.695 & 1.511 & 2.987 & 4.617 & 0.000 & 0.251 & 0.000 & 0.582 & 16.399 & 1.9 \\
\hline RO & 1.298 & 5.894 & 4.879 & 4.006 & 2.697 & 2.938 & 0.000 & 1.152 & 0.000 & 0.095 & 22.959 & 2.7 \\
\hline SE & 8.890 & 4.000 & 0.000 & 16.117 & 0.500 & 5.493 & 0.000 & 0.000 & 0.000 & 0.000 & 35.000 & 4.1 \\
\hline SI & 0.696 & 0.921 & 0.491 & 0.180 & 1.053 & 0.003 & 0.000 & 0.263 & 0.000 & 0.017 & 3.624 & 0.4 \\
\hline SK & 1.940 & 1.274 & 1.738 & 0.000 & 1.607 & 0.005 & 0.000 & 0.608 & 0.000 & 0.241 & 7.413 & 0.9 \\
\hline UK & 9.374 & 15.365 & 27.241 & 0.000 & 1.693 & 10.900 & 5.200 & 9.720 & 0.000 & 3.634 & 83.127 & 9.7 \\
\hline Total & 122.34 & 154.80 & 178.36 & 117.96 & 50.93 & 125.42 & 10.86 & 74.01 & 2.30 & 19.43 & 8564.02 & - \\
\hline$(\%)$ & 14.3 & 18.1 & 20.8 & 13.8 & 5.9 & 14.6 & 1.3 & 8.6 & 0.3 & 2.3 & - & 100.0 \\
\hline
\end{tabular}

Note that the investment costs are annualized by applying a capital recovery factor equal to 0.067 , which is computed considering a lifetime of the facilities of 20 years and an interest rate of 3\%. The operating costs are taken from OpenEI (2015) and Kost et al. (2013). The last column of Table 3 indicates the ramping capability of each technology. 
Table 3: Costs and ramping capacity of the generating technologies

\begin{tabular}{l|cc|c}
\hline Technology & $\begin{array}{c}\text { Investment } \\
\text { cost }(€ / \mathrm{kW})\end{array}$ & $\begin{array}{c}\text { Operating } \\
\text { cost }(€ / \mathrm{MWh})\end{array}$ & $\begin{array}{c}\text { Ramping } \\
\text { factor (p.u.) }\end{array}$ \\
\hline Nucl & 5400 & 11.00 & 0.05 \\
Coal & 1800 & 18.39 & 0.50 \\
CCGT & 900 & 32.28 & 0.60 \\
HRes & 2385 & 20.60 & 1.00 \\
HRoR & 3510 & 5.60 & 1.00 \\
Wons & 1602 & 3.50 & 1.00 \\
Woff & 3465 & 10.50 & 1.00 \\
SoPV & 936 & 2.70 & 1.00 \\
SoTH & 4590 & 4.60 & 0.60 \\
Biom & 2115 & 12.00 & 0.60 \\
\hline
\end{tabular}

\subsection{Data for the capacity investment model}

The following paragraphs describe specific input data considered in the investment model. The planning horizon lasts from 2017 to 2050 and investment decisions can be made at two stages: 2017 and 2030. Considering the decarbonization policies introduced at European level, we do not allow capacity expansion in coal units. Additionally, we assume that the potential of hydropower with reservoir has been already exploited along Europe and, therefore, additional units using this technology cannot be built. However, we consider that the capacity of run-of-river hydropower can be enlarged up to the $10 \%$ respect to the 2016 capacity. For the rest of generating technologies, we use as reference the predictions of the decommissioned and the prospective capacity of each generating technology in each country up to 2050 reported by the European Commission (2015). For instance, the total nuclear capacity in Germany, Spain, Belgium and the Netherlands will be decommissioned by 2050, in France it may be reduced up to $47 \%$, whereas in Hungary new capacity can be built. Most of the coal plants will be decommissioned in the most populated European countries. However, the capacity of renewable technologies, specially solar PV and wind power, are expected to significantly increase during the next years. In this way, we consider that the limit on the capacity that can be built per technology corresponds to the prediction presented in European Commission (2015) for 2050, except for the wind and solar PV units, for which we assume a 35\% higher potential capacity than that stated in European Commission (2015).

In order to ensure a renewable-dominated European power system, a limit on the total energy generated by nuclear, coal and CCGT units equal to $20 \%$ of the total generation is enforced to all countries belonging to the European Union (excluding therefore Switzerland and Norway). In addition, a security margin equal to $2 \%$ of the energy demand is considered to ensure the demand supply under unexpected situations (see constraint (10)). The maximum energy capacity of storage units that can be installed in each country is equal to $25 \%$ of the daily consumption of the most representative day of 2016 (the method used to select the most representative days of the year is explained below). For the power capacity, we impose a maximum value of the ratio energy-power capacity equal to 15 . The round-trip rate is equal to 0.92 and the investment costs are $45 € / \mathrm{MWh}$ for the energy capacity and $900 € / \mathrm{kW}$ for the power capacity (see IRENA, 2017).

On the other hand, to establish the limit of the investment budget we consider the gross domestic product (GDP) of 2016 of the countries in the European Union. The investment budget is limited to 3\% of the GDP in the countries with the highest GDP: Austria, Belgium, Denmark, Finland, France, Germany, Italy, the Netherlands, Spain, Sweden, and United Kingdom. The investment budget for the rest of countries is fixed to $2 \%$ of their GDP.

Finally, the hourly variability of the renewable power production and the demand level along the year is accounted for by considering a set of representative days. The representative days are selected using the fast-forward scenario reduction algorithm described in Growe-Kuska et al. (2003) over the hourly net demand (consumption minus intermittent renewable power) in the European power system in year 2016. The objective of this algorithm is to represent the set of 365 days with a reduced set of representative days that are close to the original set in terms of a probability distance. The algorithm computes the weight for each selected day. Then, for the investment model, we consider a set of 25 representative days, i.e. a total of 600 hours.

\subsection{Data for the daily operating model}

Additional clarifications and specific data needed to describe the operation of the European power system are added next. The operating model is applied to the power system resulting from the multi-stage capacity expansion model for 2050. Therefore, we assume that: i) the new generating capacity corresponds to the expected value obtained from the investment model, considering the decommissioned and the new capacity built; ii) the demand grows $20 \%$ respect to the values of 2016; and iii) the investment cost of the generating facilities decreases in $1.7 \%$ respect to 2016 values, which is the expected value among the considered scenarios.

From an operational point of view, generating units are divided into two sets: dispatchable units $\left(\Omega^{\mathrm{Di}}\right)$, namely CCGT, coal, nuclear, hydroelectric (with reservoir and run-of-river), biomass, and CSP, and intermittent units $\left(\Omega^{\mathrm{It}}\right)$, namely wind and solar 
PV units. We consider that storage units are managed by the TSO as a flexible resource to maintain the reliability of the system.

For the day-ahead scheduling, a minimum reserve requirement is set based on the policy devised by NREL (2010), where reserve should cover at least 3\% of the demand and 5\% of the intermittent production in each hour. All generating units except for the nuclear can provide reserve capacity and they do it at a cost equal to $1 \%$ of their operating cost. Besides, wind and solar PV units are considered to provide reserve capacity up to $30 \%$ of the available power predicted in the day ahead (see Gesino et al., 2011; Lin et al., 2009). The reserve capability of storage units is also limited to 5\% of their power capacity.

\section{Methodology}

This section describes the methodology proposed to determine the optimal capacity expansion of the European power system and its daily operation in the target year 2050. For the sake of clarity, the formulations of the proposed models are provided in $\mathrm{B}$ and $\mathrm{C}$, respectively.

\subsection{Capacity expansion model}

The goal is to determine the generating and storage capacity expansion decisions required to transform the current European power system into a renewable-dominated one. To do that it is considered that investment decisions in generating and storage capacity are made in two stages, namely years 2030 and 2050. The hourly variability of the renewable power production and the demand are accounted for by characterizing each of the target years (2030 and 2050) by a set of 25 representative days divided into hourly periods. The representative days and their weights are selected using the fast-forward scenario reduction algorithm (see Growe-Kuska, 2003) over the historical hourly net demand in 2016. According to the data provided by European Commission (2015), we consider that part of the existing generating capacity is decommissioned during the planning horizon. The transmission capacity is also considered using the dc representation of the power system.

The planning of the power system is a long-term exercise in which multiple uncertainties are involved. In this proposal, we consider the demand growth and the capital cost of the generating and storage units as the most determinant uncertain parameters. We use stochastic programming to model the decision-making process involved in this problem (see, e.g. Birge ands Louveaux, 1997 and Conejo et al., 2010). Therefore, the possible values of these uncertain parameters are represented by a set of scenarios, which are defined regarding the predictions made by the authorities and expert energy agencies. We consider 3 demand growth scenarios, which are generated assuming a minimum and maximum increase of the demand of $15 \%$ and $25 \%$, respectively. Two scenarios of investment costs of generating technologies are generated based on the projections made by IEA (2016). Similarly, two scenarios of the investment costs of the storage units are randomly generated considering a maximum decrease of $20 \%$ respect to the current value. Consequently, a total number of 36 equiprobable scenarios is considered $(3 \times 2 \times 2 \times 3)$.

Therefore, the proposed investment model is formulated as a multi-stage stochastic programming problem whose decisionmaking process is represented in Figure 2. This figure represents the scenario tree of a three-stage investment model involving the long-term uncertainties. The planning horizon starts in 2017 and ends in 2050 and is divided into two periods: 2017-2029 and 2030-2050. At the beginning of each period, here-in-after called stage, investment decisions are made. In the first stage (2017), investment decisions are made for all considered scenarios. At this stage, investment costs are assumed to be known and they are equal to their current value. In the second stage (2030), new investment decisions can be made considering the realization of the demand growth in each scenario during the first period (2017-2029), and the realization of the investment costs in each scenario at the second stage. Then, during the second period (2030-2050) the demand growth is realized. In addition, note that in each decision node of the scenario tree (black dot in the figure), except for the first node, the system is operated and the demand is supplied considering the generating system defined at the corresponding stage and the hourly demand level and available renewable power. 


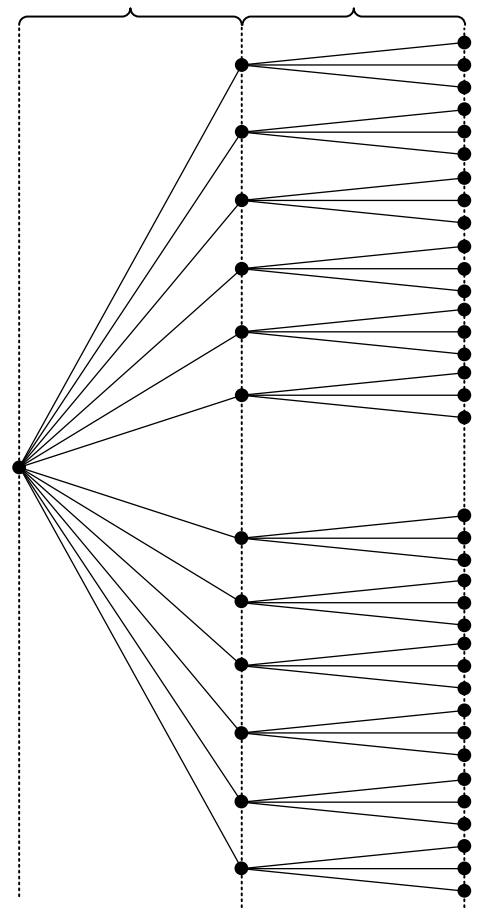

Figure 2: Representation of the scenario tree in the investment model.

\subsection{Operating model}

In this section, we describe the operating model used to test the performance of the European power system resulting from the solution of the investment model explained above. The proposed market structure is based on the co-optimization of the energy and up/down reserve in the day-ahead (DA) market taking into account the variability that can be found in the real-time (RT) operation. In the operating model, we consider as uncertain parameters the demand and the wind and solar productions in each hour of the day.

From a mathematical point of view, the operating model is formulated as a two-stage stochastic programming problem, where the first stage represents the DA market and the second stage is used to characterize the RT operation (see Domínguez et al., 2014). Hence, energy and up and down reserve capacities are scheduled in the DA considering the predicted value of the demand and the intermittent production. In the RT operation, the needed reserves are deployed to counteract the deviations between the DA prediction and the actual values of the uncertain parameters.

The uncertainty related to the hourly demand level and the renewable power availability in the RT operation is characterized using a set of scenarios. The scenarios are generated for each hour of the considered day using historical data of 2016 according to the following procedure: first, we consider the DA predictions made by ENTSO-E of the demand level and the intermittent renewable production for each of the 24 hours of a certain day used to clear the DA energy market; second, the probability distribution functions characterizing the forecast error between the DA predictions and actual values in the RT operation are computed (note that in the ENTSO-E transparency platform ${ }^{10}$ we can find the DA prediction and the actual values); and third, using the estimated forecast error distributions and DA values, 100 scenarios of demand and intermittent renewable production are randomly generated for each of the 24 hours of the day, which are afterwards reduced to 10 scenarios using the scenario reduction algorithm described in Growe-Kuska et al. (2003). This procedure follows for each day of the year.

Finally, as typically done in market-clearing models used in European power systems, no unit commitment variables are considered. The demand is assumed to be uncertain but inelastic, and the transmission network has been represented using a dc model.

\footnotetext{
${ }^{10}$ See ENTSO-E transparency platform available at: https://transparency.entsoe.eu/
} 


\section{Results and Discussion}

In this section we include the results obtained by solving the capacity expansion and operating models described above. For the sake of clarity, the discussion about the main results obtained from our study is divided into two subsections, those corresponding to the capacity expansion plan and those related to the system operation. All mathematical problems have been solved using GAMS (see Rosenthal, 2008) and CPLEX 12.6.1 ${ }^{11}$ in a linux-based server of four 3.0 GHz processors and $250 \mathrm{~GB}$ of RAM.

\subsection{Results: capacity expansion model}

First, we analyze the results obtained from the capacity expansion model. The resulting problem comprises 16.26 millions of variables and 26.36 millions of equations. The computational time required to solve the problem is about 130 hours.

Figure 3 represents the expected total generating capacity per technology in each country at the end of the first and the second periods of the planning horizon, namely in 2030 and 2050, respectively. Among others, it is notorious the high increase in the total generating capacity in most of the countries in 2050, doubling, in many cases, the existing capacity in 2016. This is a straightforward effect caused by the implementation of the decarbonization policies that encourage investments in renewablebased power plants to replace fossil-fueled generating units. More precisely, since wind and solar units are characterized by low capacity factors, higher investments in these technologies are needed to ensure the demand supply.

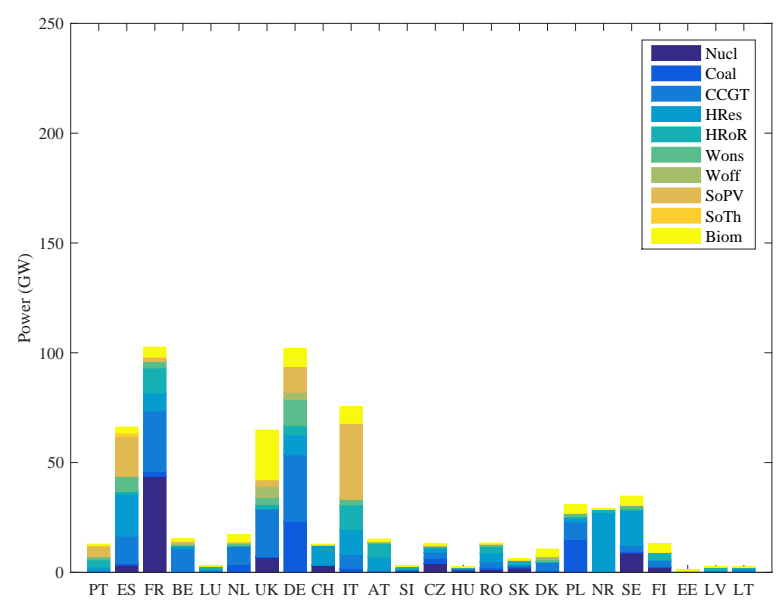

(a) 2030

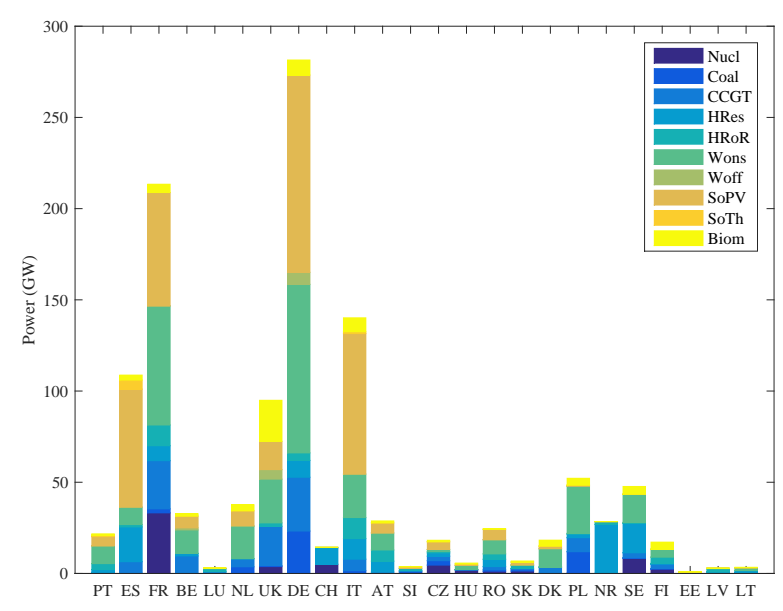

(b) 2050

Figure 3: Expected total generating capacity per technology and country in 2030 and 2050.

Specifically, the expected total new capacity to be built during the whole planning horizon is $880.65 \mathrm{GW}$. However, note that only $17 \%$ of the total new capacity is built between 2017 and 2030. The low amount of new capacity installed before 2030 is explained by two facts: first, there is an excess of generating capacity at the end of 2016 in many European countries, and second, the high reduction in the investment costs of renewable technologies that are expected after 2030 makes the investment decisions to be postponed.

The expected total new generating capacity per technology is distributed as follows: $5.88 \mathrm{GW}$ of nuclear, $86.43 \mathrm{GW}$ of CCGT, 5.09 GW of run-of-river hydro, $332.36 \mathrm{GW}$ of onshore wind, $7.54 \mathrm{GW}$ of offshore wind, $366.84 \mathrm{GW}$ of solar PV, 5.88 GW of CSP, and $70.63 \mathrm{GW}$ of biomass. It can be observed that a large share of the new generating capacity corresponds to solar PV in most of the countries. As expected, the countries with the highest demand (Germany, UK, France, Italy and Spain) require a high expansion in the generating capacity. It is also worth noting that countries such as France, Germany, UK or Poland are expected to build additional capacity of CCGT units. On the contrary, countries like Spain, France or Italy base their capacity expansion in solar PV, wind and, less significant, biomass power.

As a particular result, note that Figure 3 shows that almost all the coal and CCGT capacity in Germany is maintained while the solar PV and wind capacity significantly increases due to the increment in the demand. In the case of France, it is relevant the diversification of its generating mix, moving from a nuclear-based system to a renewable-dominated one. Solar PV will dominate the generating systems of Spain and Italy, while a high expansion in wind power is expected in UK, Poland, the Netherlands and Belgium.

\footnotetext{
${ }^{11}$ See The IBM CPLEX. Available at: http://www-01.ibm.com/software/commerce/optimization/cplex-optimizer/.
} 


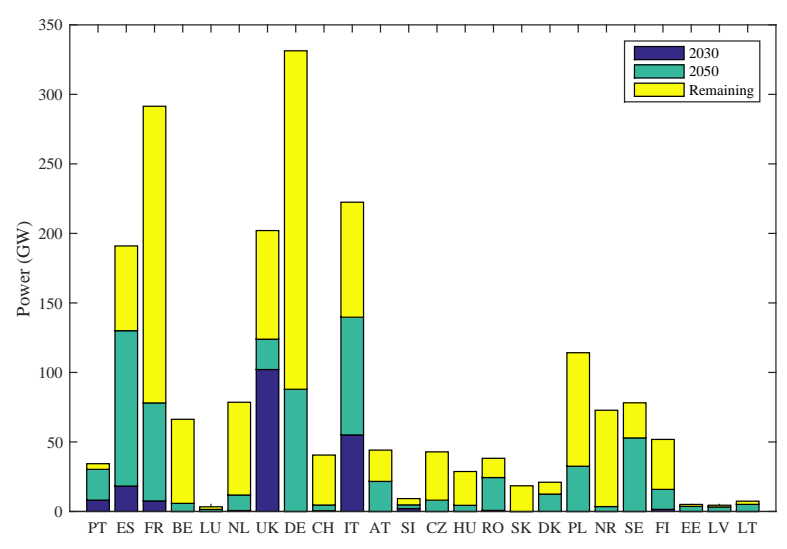

(a) Energy capacity

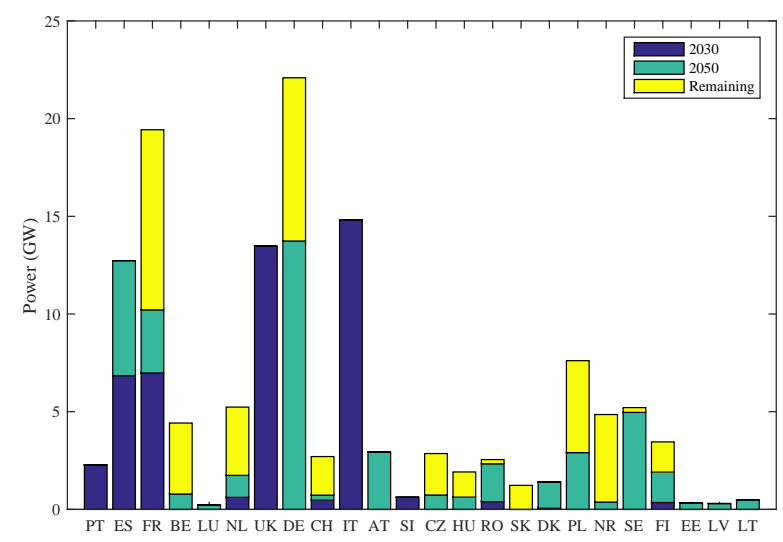

(b) Power capacity

Figure 4: Expected total storage capacity built in each country in the end of the planning horizon.

The expansion in the storage capacity is represented in Figure 4. Specifically, these figures represent the energy and power capacity to be built until 2030 and 2050, respectively, as well as the remaining available storage capacity that is not built. As expected, the higher storage capacity is built in those countries with higher consumption.

Figure 5 depicts the expected demand and generation in years 2030 and 2050 for each country and it is used to analyze the relation between generating capacity and demand. In this figure, we can observe that the transformation of the current thermal-based European power system into a renewable-dominated one causes that traditionally exporter countries may reverse their situation and become energy importer countries. This is the case of France that, in 2050, is expected to become a power importer because of its progressive decommissioning of nuclear capacity. Opposite to this, countries that were energy importers in the past, as Italy, are expected to be exporters in 2050 because of its large investments in renewable-based power plants.

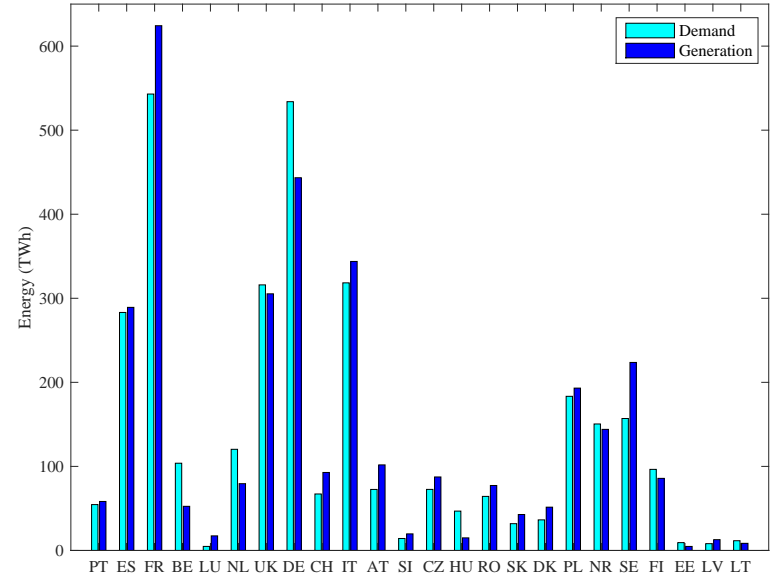

(a) 2030

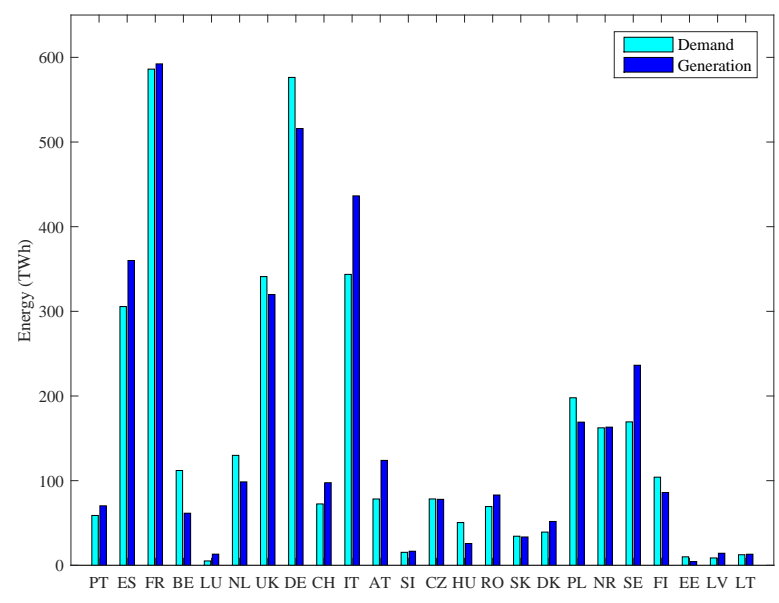

(b) 2050

Figure 5: Expected demand and generation in a single year of each planning period for each country.

Table 4 provides additional results on the 2050 power system. In particular, columns 2-4 indicate the share of renewable, nuclear and fossil-fuel capacity in each country, column 5 gives the rate between the power storage and generating capacity, and column 6 indicates the share of the storage power capacity built respect to the maximum available. Considering columns 2-4, we can notice that, in 2050, renewable capacity is expected to cover significant shares of the total installed capacity in all countries. More precisely, this share will range between $40 \%$ and $70 \%$ in 8 countries (CH, CZ, EE, HU, LU, PL, SI, and SK); between $70 \%$ and $80 \%$ in 7 countries (BE, FI, FR, LV, NL, SE, and UK); between $80 \%$ and $90 \%$ in 4 countries (DE, DK, LT, and RO); and above $90 \%$ in 5 countries (AT, ES, IT, NR, and PT). The nuclear power remains representative ( $\geq 20 \%)$ only in the generating systems of Switzerland, Hungary, and Czech Republic. Besides, fossil-fuel capacity will represent more than $20 \%$ of the generating system in 9 countries (BE, CZ, EE, LU, LV, NL, PL, SK, and UK). Investments in storage capacity are strictly 
connected with the amount of renewable power plants built in the different countries. It is remarkable the comparatively low storage power capacity installed in Germany, France or the Netherlands, whereas in Portugal, Spain, Italy, UK among others, more than $60 \%$ of the available capacity is installed. Looking at the rate generating capacity and peak demand, we observe that the value of 2050 almost duplicates the one of 2030 in many countries, which is due to the high increase of the intermittent renewable capacity.

Table 4: Share of renewable, nuclear and fossil-fuel capacity by 2050, rate storage capacity built, rate energy and power storage capacity, and rates generating capacity against peak demand (\%).

\begin{tabular}{c|ccc||cc||cc}
\hline & \multicolumn{2}{|c||}{ Generating capacity in 2050 } & \multicolumn{2}{c||}{ Storage in 2050 } & \multicolumn{2}{c}{ Capacity vs. Peak demand } \\
Country & Renewable & Nuclear & Fossil-fuel & Energy built & Energy/power & 2030 & 2050 \\
\hline AT & 97.28 & 0.00 & 2.72 & 48.99 & 7.35 & 1.23 & 2.17 \\
BE & 70.61 & 0.00 & 29.39 & 8.78 & 7.40 & 1.06 & 2.09 \\
CH & 65.26 & 34.74 & 0.00 & 11.42 & 6.36 & 1.30 & 1.36 \\
CZ & 48.02 & 25.19 & 26.78 & 18.95 & 11.04 & 1.14 & 1.45 \\
DE & 81.26 & 0.00 & 18.74 & 26.53 & 6.40 & 1.22 & 3.13 \\
DK & 80.99 & 0.00 & 19.01 & 59.43 & 8.91 & 1.66 & 2.65 \\
EE & 43.46 & 0.00 & 56.54 & 72.27 & 10.84 & 0.75 & 0.62 \\
ES & 94.07 & 0.00 & 5.93 & 68.07 & 10.21 & 1.58 & 2.41 \\
FI & 70.89 & 13.32 & 15.79 & 30.66 & 8.32 & 0.82 & 0.99 \\
FR & 71.02 & 15.57 & 13.41 & 26.79 & 7.65 & 1.08 & 2.09 \\
HU & 63.02 & 35.13 & 1.84 & 15.39 & 7.04 & 0.39 & 0.75 \\
IT & 94.42 & 0.00 & 5.58 & 62.82 & 9.42 & 1.42 & 2.44 \\
LT & 83.45 & 0.00 & 16.55 & 68.95 & 10.34 & 1.30 & 1.63 \\
LU & 66.90 & 0.00 & 33.10 & 44.32 & 6.67 & 4.23 & 3.90 \\
LV & 72.92 & 0.00 & 27.08 & 72.67 & 10.90 & 1.89 & 2.01 \\
NL & 78.51 & 0.00 & 21.49 & 15.08 & 6.80 & 0.86 & 1.74 \\
NR & 100.00 & 0.00 & 0.00 & 4.84 & 9.44 & 1.07 & 0.98 \\
PL & 62.43 & 0.23 & 37.34 & 28.50 & 11.20 & 1.09 & 1.71 \\
PT & 97.27 & 0.00 & 2.73 & 88.17 & 13.23 & 1.50 & 2.34 \\
RO & 84.73 & 4.96 & 10.31 & 63.82 & 10.46 & 1.27 & 2.17 \\
SE & 76.26 & 17.50 & 6.24 & 67.70 & 10.66 & 1.19 & 1.52 \\
SI & 62.69 & 18.28 & 19.03 & 51.12 & 7.67 & 1.32 & 1.56 \\
SK & 60.17 & 19.31 & 20.52 & 0.00 & 0.00 & 1.31 & 1.33 \\
UK & 72.76 & 3.96 & 23.27 & 61.33 & 9.20 & 1.01 & 1.37 \\
\hline
\end{tabular}

Finally, Table 5 shows the distribution of the resulting total expected cost among different concepts. Therefore, according to the information provided in this table, the transformation of the European power system into a decarbonized system will cost around 1790 billion euros. As reference, this value represents about $60 \%$ of the GDP of Germany in 2016.

Table 5: Total investment and operating costs.

\begin{tabular}{l|r|c}
\hline Investment cost in generating capacity & 1622.5 bill $€$ & $50 \%$ \\
Investment cost in storage capacity & 167.9 bill $€$ & $5 \%$ \\
Operating cost & 1485.9 bill $€$ & $45 \%$ \\
\hline Total cost & 3276.3 bill $€$ & $100 \%$ \\
\hline
\end{tabular}

\subsection{Results: system operation model}

This section analyzes the operation of the European power system in 2050. First, we compare the day-ahead scheduling in a representative day for the power system of the last known year, i.e. 2016, and for the resulting power system in 2050. In our analysis, this representative day corresponds to September $25^{\text {th }}$ that is the day selected in the first iteration of the fast-forward scenario reduction algorithm (see Growe-Kuska et al., 2003) as explained in Section 2.2. In both the 2016 and 2050 systems, we consider a demand growth of $20 \%$ respect to the demand in 2016, hence, the only difference between the two cases corresponds with the generating system composition. In a second subsection, we analyze the most relevant results of the system operation during the whole year. 


\subsubsection{Single-day operation}

In this subsection we analyze the power system operation for a representative day of the year. Figures 6 and 7 show the energy and reserve capacity schedules in the day-ahead market, respectively, in years 2016 and 2050. As it can be observed in Figure $6 \mathrm{~b}$, the demand will be mainly supplied by solar PV in the central hours of the selected day in 2050 . Note that during these hours, energy storage units are charged (negative power in Figure 6b). It is also worth noting that energy storage units are discharged in the hours prior to the starting of the PV units (hours 6-9), and also during the hours when PV units significantly decrease their power output (hours 22-24). In this manner, storage units provide the required flexibility to accommodate the renewable power production of the system to the demand. Respect to the reserve needs, according to the criterion that we established to determine the minimum reserve capacity (red line in Figure 7), the higher the expected intermittent renewable power, the higher the reserve needs. Moreover, while the reserve capacity is mainly provided by coal and CCGT units in 2016, renewable and storage units provide that capacity in 2050.

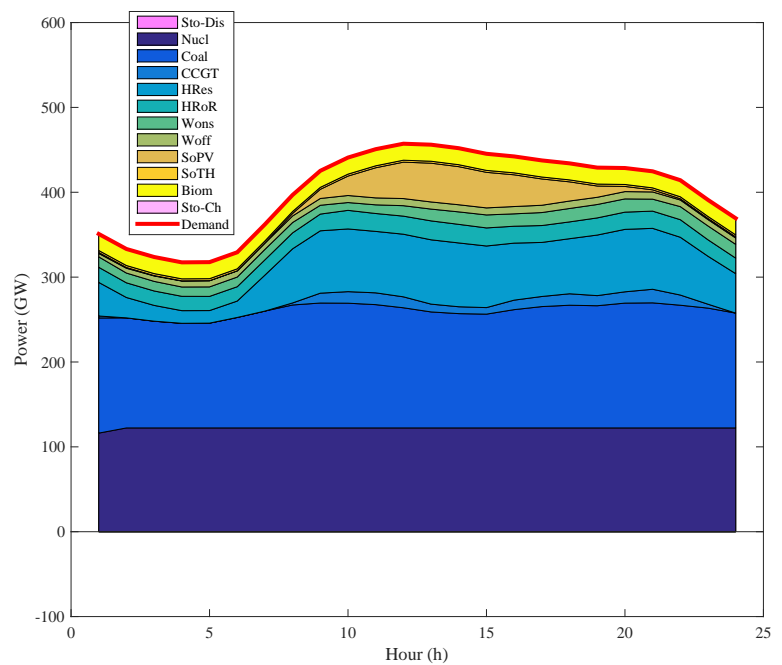

(a) 2016

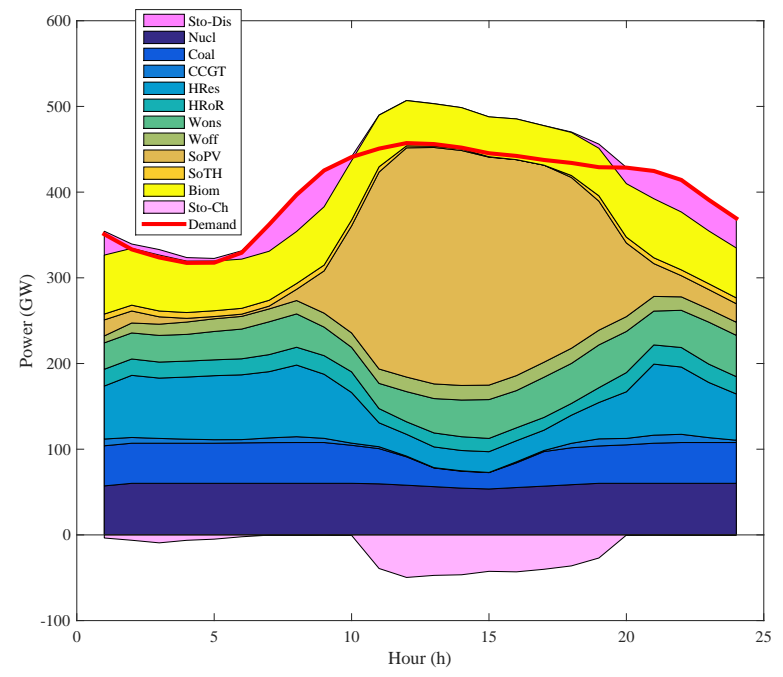

(b) 2050

Figure 6: Scheduling of the day-ahead energy market in the whole system in 2016 and 2050.

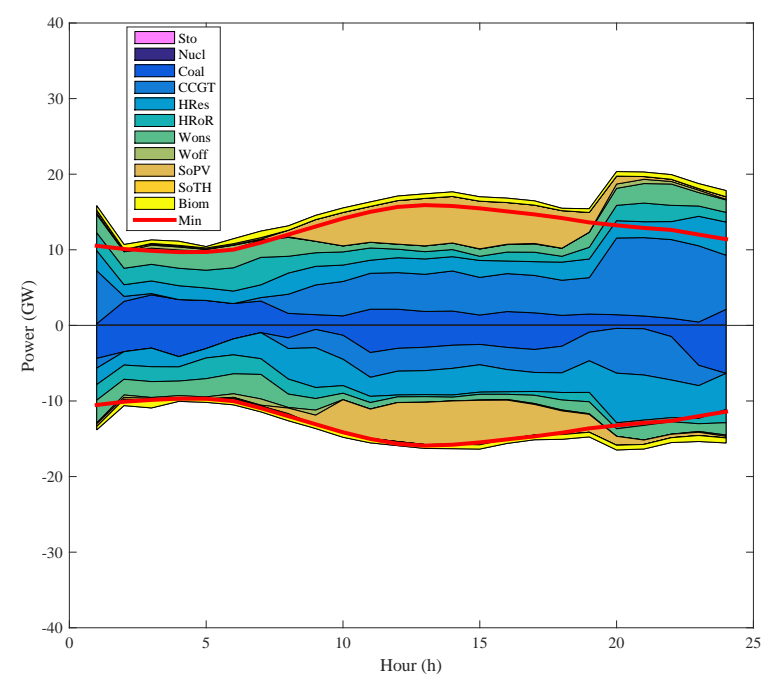

(a) 2016

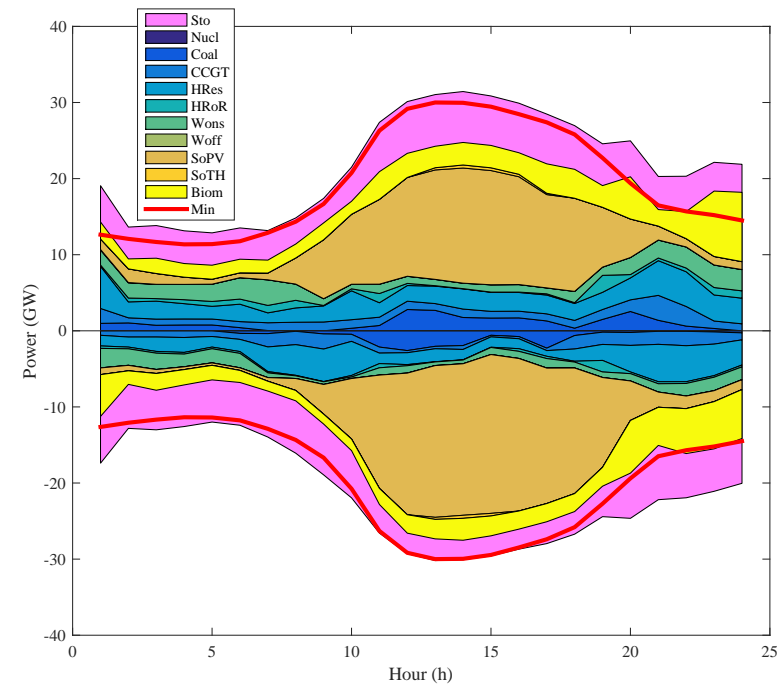

(b) 2050

Figure 7: Scheduled reserve capacity in the day ahead in the whole system in 2016 and 2050. 
Figure 8 depicts the day-ahead energy prices in each country in 2016 and 2050 for the representative day. These prices correspond to the values of the dual variable of the day-ahead energy balance constraint (24), which is included in C. The impacts of the increasing integration of renewable energy sources are twofold: first, it leads to a reduction of the electricity prices in 2050 compared to their corresponding levels in 2016; secondly, it introduces a comparatively higher variability both among countries and hours in 2050 prices compared to the ones registered in 2016 . The existence of different prices among the countries is affected by the congestion in some transmission lines.

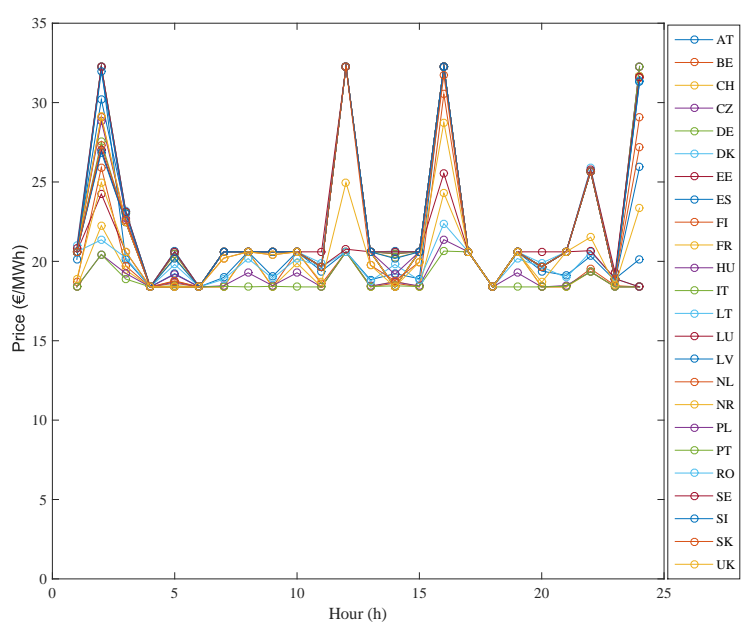

(a) 2016

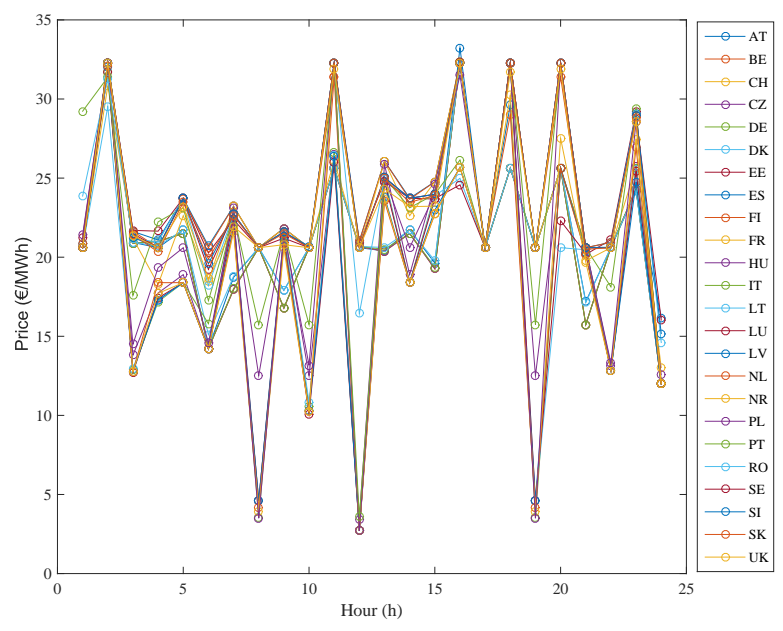

(b) 2050

Figure 8: Electricity prices in the day-ahead market per country in 2016 and 2050.

\subsubsection{One-year operation}

Once looked into the detailed system operation during a day, we test the operation of the resulting European power system in 2050 during a whole year. Figure 9 shows the cumulative day-ahead energy (left) and reserves (right) scheduled by each generating technology for each month of 2050. In Figure 9a we observe that a high share of the demand will be supplied by solar PV power plants in the central months of the year, while in the colder months, with small solar radiation, the wind and hydro power plants will compensate the reduction in the solar radiation by increasing their power output. In addition, this figure shows how much higher is the demand in winter in comparison with that in summer. The reserve capacity will be mainly provided by wind and solar PV power plants and the storage.

Figure 10 depicts the expected wind and solar PV power spillage along the year, which becomes very significant in the central months of the year.

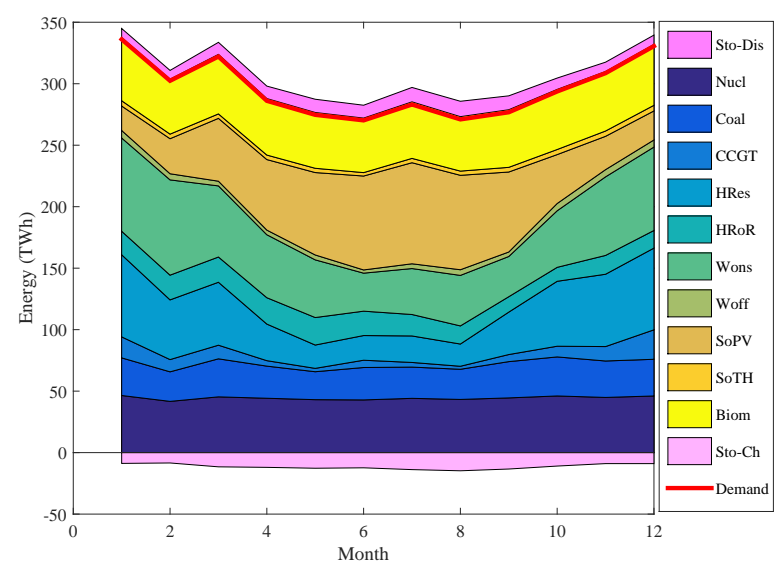

(a) Energy

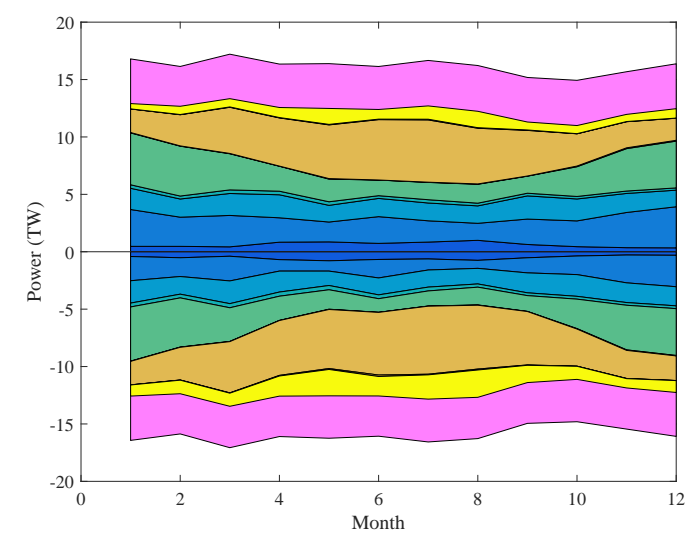

(b) Up and down reserves

Figure 9: Cumulative day-ahead schedule in each month of 2050. 


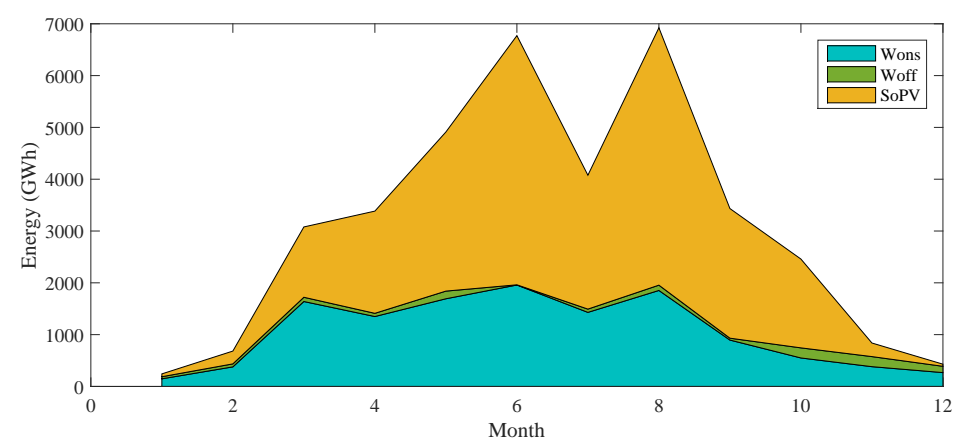

Figure 10: Average intermittent renewable power spillage in 2050.

Figure 11 represents the source of the energy produced and the carbon emissions in each country in 2050. The percentage of renewable production is depicted in Figure 11a. Note that only 5 countries have a renewable production less than 50\%. It is also remarkable the case of Norway, where $100 \%$ of the electricity production is renewable. Figure $11 \mathrm{~b}$ represents the expected energy produced by nuclear units. Observe that 11 countries have installed nuclear power plants by 2050 and their production represents $14.9 \%$ of the total. The energy obtained from fossil-fuel units is shown in Figure 11c. A significant case is the generating mix of Poland, where $48.9 \%$ of the production is obtained from fossil-fuel units. However, the average among the 24 European countries represents only the $12.3 \%$. Figure 11d shows the expected carbon emissions per country. Obviously, this figure is qualitatively similar to Figure 11c, since countries with a higher production based on fossil-fuel units are also the ones that pollute more. It is worth to note that only 6 countries emit more than $100 \mathrm{gCO}_{2} / \mathrm{kWh}$.

Further, Table 6 provides the expected $\mathrm{CO}_{2}$-equivalent emissions produced by coal and CCGT units in each country in 2030

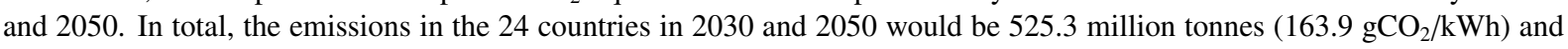
369.7 million tonnes $\left(103.3 \mathrm{gCO}_{2} / \mathrm{kWh}\right)$, respectively. The reduction in the emissions in 2050 respect to 1990 would represent the $77 \%$ in the electricity sector (the 1990 values are available on Eurostat). ${ }^{12}$

Table 6: Expected $\mathrm{CO}_{2}$-equivalent emissions per country (Million tonnes).

\begin{tabular}{c|ccccccccccc}
\hline Country & AT & BE & CZ & DE & DK & EE & ES & FI & FR & HU & IT \\
\hline 2030 & 1.29 & 21.33 & 21.20 & 201.23 & 5.45 & 0.40 & 9.08 & 4.84 & 23.57 & 1.40 & 14.11 \\
2050 & 0.31 & 12.53 & 15.78 & 154.26 & 0.93 & 0.30 & 0.97 & 3.31 & 14.60 & 0.15 & 6.37 \\
\hline Country & LT & LU & LV & NL & PL & PT & RO & SE & SI & SK & UK \\
\hline 2030 & 0.88 & 0.93 & 0.10 & 49.65 & 127.20 & 0.27 & 8.92 & 4.53 & 2.48 & 6.75 & 19.69 \\
2050 & 0.21 & 0.22 & 0.17 & 32.64 & 88.12 & 0.04 & 6.79 & 1.66 & 1.34 & 6.17 & 22.88 \\
\hline
\end{tabular}

\footnotetext{
${ }^{12}$ Eurostat, Statistics explained. Available at: https://ec.europa.eu/eurostat/statistics-explained/index.php/ Greenhouse_gas_emission_statistics_-_emission_inventories\#Trends_in_greenhouse_gas_emissions
} 


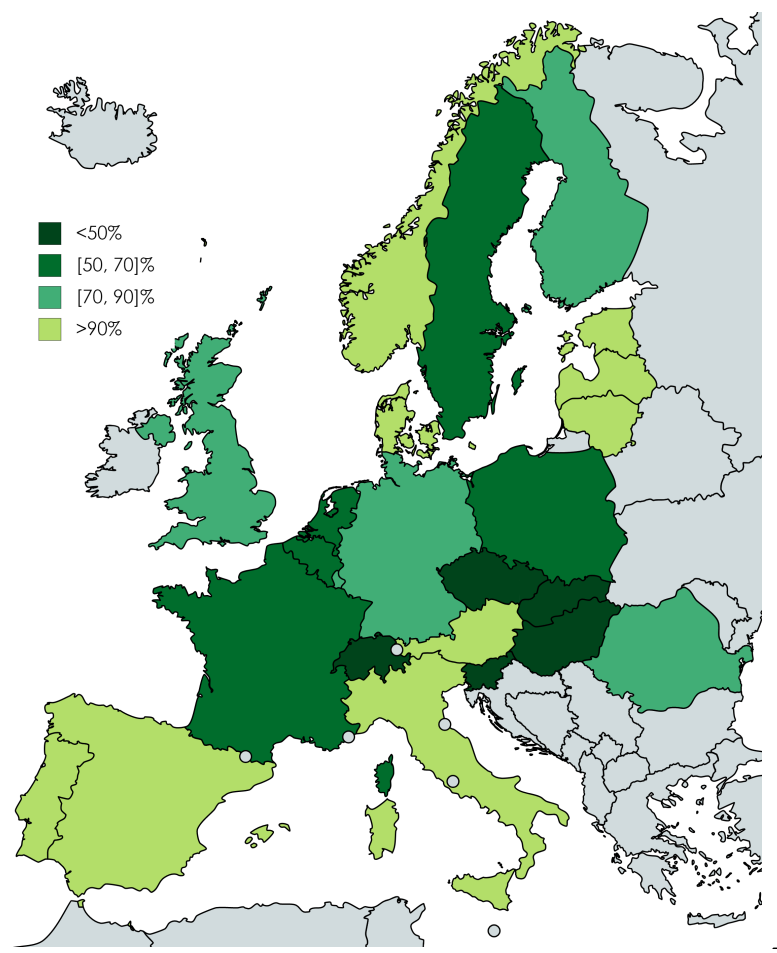

(a) Energy produced by renewable units (\%)

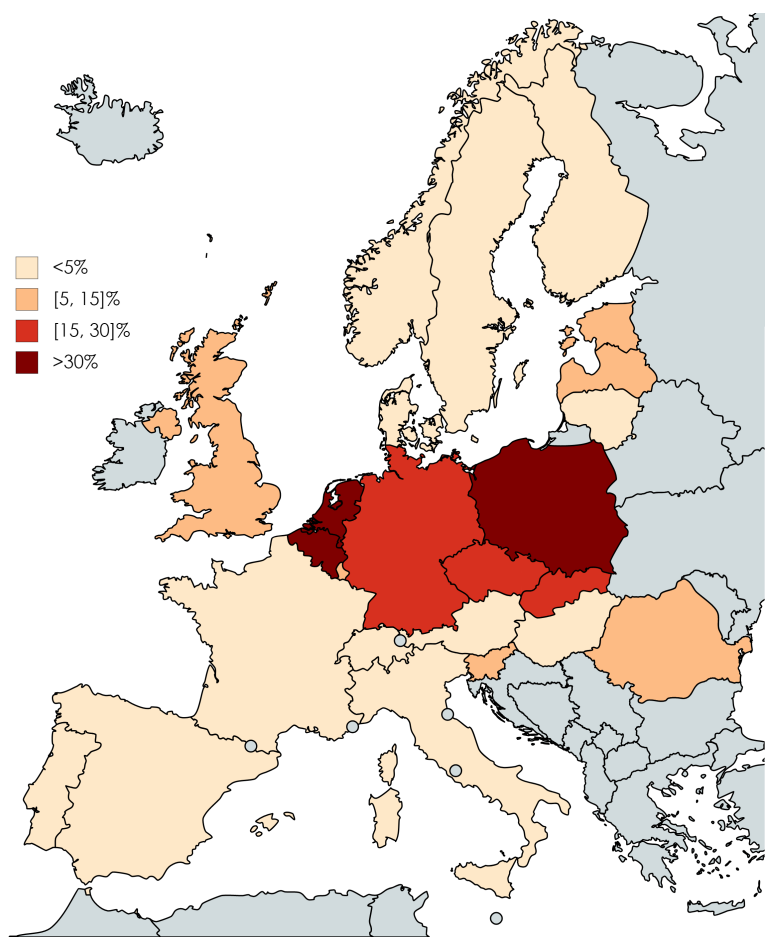

(c) Energy produced by fossil-fuel units (\%)

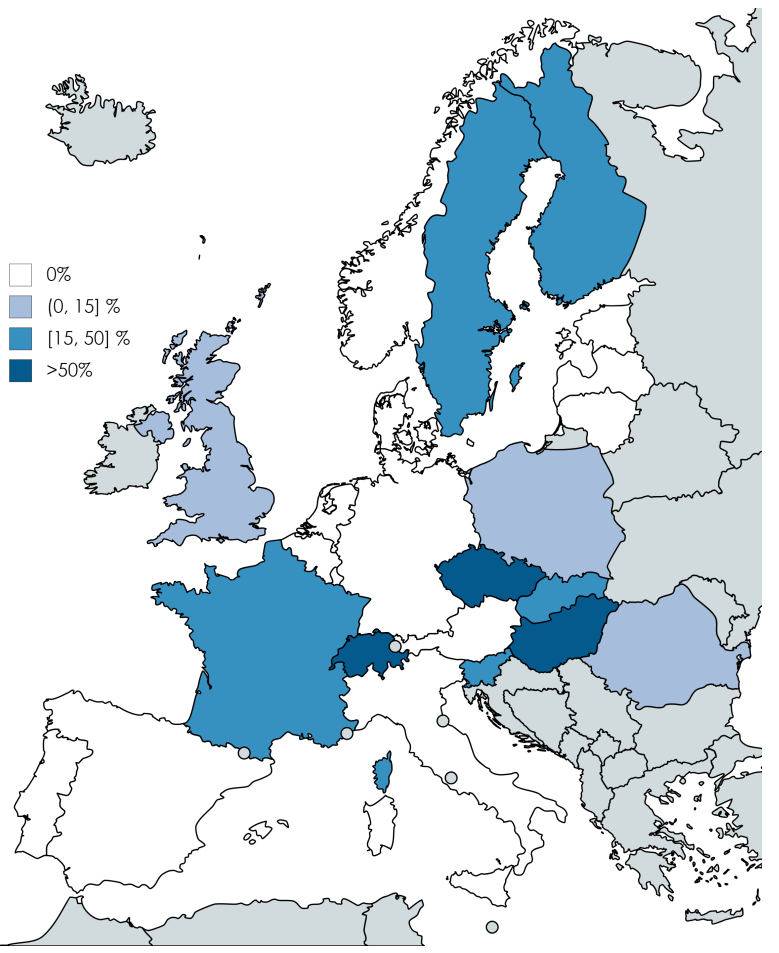

(b) Energy produced by nuclear units $(\%)$

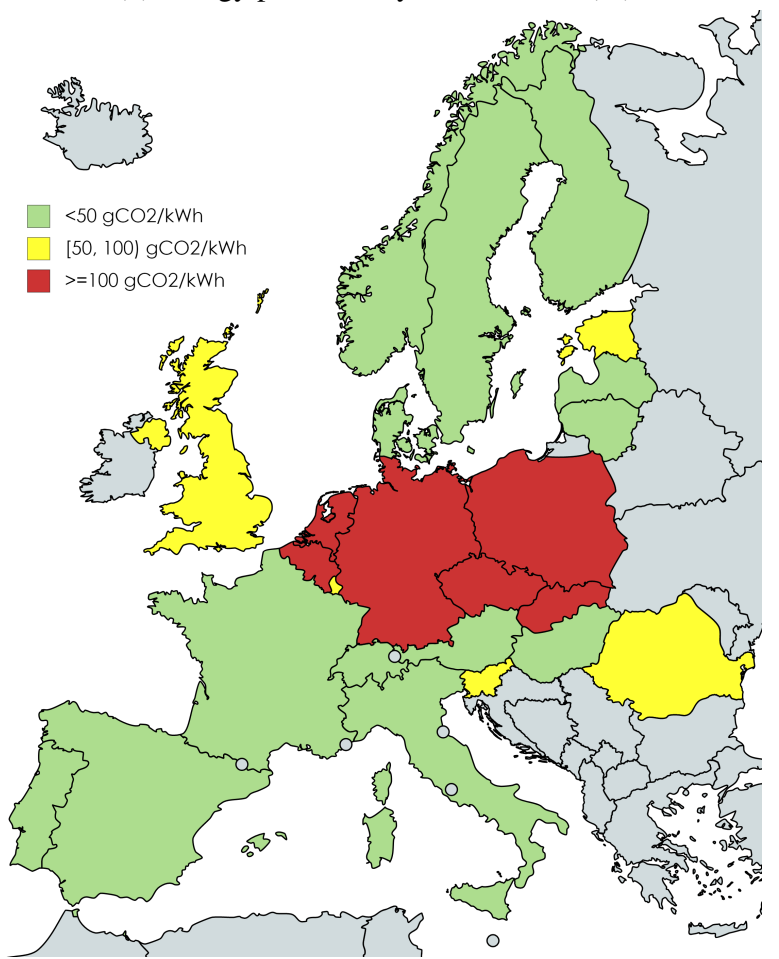

(d) $\mathrm{CO}_{2}$ emissions $\left(\mathrm{grCO}_{2} / \mathrm{kWh}\right)$

Figure 11: Energy produced and emissions per country in 2050.

To finish with the technical results, Table 7 provides the expected number of hours in which the transmission lines are congested in the day-ahead schedule along 2050. This table shows that there are four lines that are congested more than half of the hours of the year. 
Table 7: Expected hours of line congestion in 2050.

\begin{tabular}{c|cc|c||c|cc|c}
\hline Line & Origin & Destiny & Hours & Line & Origin & Destiny & Hours \\
\hline 1 & PT & ES & 601 & 21 & IT & SI & 1 \\
2 & ES & FR & 3600 & 22 & AT & SI & 77 \\
3 & FR & BE & 4307 & 23 & AT & CZ & 2194 \\
4 & FR & CH & 396 & 24 & AT & HU & 4146 \\
5 & FR & UK & 0 & 25 & HU & RO & 3238 \\
6 & FR & DE & 665 & 26 & HU & SK & 0 \\
7 & FR & IT & 143 & 27 & SK & CZ & 0 \\
8 & BE & NL & 1250 & 28 & SK & PL & 618 \\
9 & NL & UK & 4867 & 29 & PL & CZ & 4105 \\
10 & NL & DE & 0 & 30 & PL & SE & 3059 \\
11 & DE & LU & 0 & 31 & PL & LT & 187 \\
12 & DE & CH & 136 & 32 & DK & NR & 4750 \\
13 & DE & AT & 0 & 33 & DK & SE & 3460 \\
14 & DE & CZ & 0 & 34 & NR & NL & 5645 \\
15 & DE & DK & 0 & 35 & NR & SE & 0 \\
16 & DE & PL & 0 & 36 & SE & FI & 478 \\
17 & DE & SE & 994 & 37 & FI & EE & 1 \\
18 & CH & IT & 0 & 38 & EE & LV & 0 \\
19 & CH & AT & 173 & 39 & LV & LT & 0 \\
20 & IT & AT & 4829 & 40 & LT & SE & 1651 \\
\hline \multicolumn{7}{|r|}{}
\end{tabular}

Then, we provide the daily electricity prices and the profits obtained by the producers along the year. Table 8 indicates the average day-ahead energy prices in each month and in each country along 2050.

Table 8: Average day-ahead energy price per country and per month in 2050 (€/MWh).

\begin{tabular}{c|cccccccccccc}
\hline Country & Jan. & Feb. & Mar. & Apr. & May & Jun. & Jul. & Ago. & Sep. & Oct. & Nov. & Dec. \\
\hline AT & 22.5 & 21.1 & 22.0 & 19.7 & 18.5 & 21.4 & 19.5 & 19.8 & 20.8 & 22.8 & 22.9 & 24.0 \\
BE & 32.0 & 24.9 & 27.7 & 27.4 & 27.9 & 31.3 & 28.9 & 28.5 & 30.1 & 30.3 & 28.7 & 30.2 \\
CH & 23.4 & 20.7 & 19.8 & 17.5 & 15.7 & 16.2 & 16.5 & 16.0 & 18.6 & 21.8 & 22.6 & 26.4 \\
CZ & 119.5 & 22.8 & 22.9 & 19.2 & 17.9 & 18.3 & 17.6 & 17.8 & 19.2 & 23.1 & 24.0 & 41.6 \\
DE & 36.1 & 21.9 & 22.8 & 19.9 & 18.0 & 20.3 & 19.2 & 18.9 & 21.5 & 23.2 & 23.4 & 25.5 \\
DK & 23.8 & 19.4 & 22.7 & 17.6 & 17.1 & 18.4 & 15.7 & 17.0 & 19.3 & 18.4 & 19.1 & 17.9 \\
EE & 963.2 & 23.0 & 22.8 & 21.0 & 20.2 & 20.6 & 20.7 & 19.5 & 21.5 & 21.2 & 22.7 & 20.9 \\
ES & 22.7 & 20.0 & 16.8 & 15.6 & 13.0 & 11.6 & 13.1 & 12.5 & 15.5 & 19.0 & 20.9 & 24.8 \\
FI & 1326.0 & 22.3 & 21.8 & 20.6 & 20.0 & 19.9 & 19.9 & 18.8 & 20.4 & 20.3 & 21.7 & 19.7 \\
FR & 32.7 & 21.5 & 20.4 & 17.5 & 14.9 & 15.2 & 15.7 & 14.6 & 18.0 & 21.8 & 23.2 & 30.8 \\
HU & 644.2 & 30.8 & 31.3 & 21.9 & 20.9 & 25.1 & 26.4 & 23.3 & 28.4 & 29.4 & 31.5 & 663.9 \\
IT & 21.4 & 17.8 & 13.7 & 12.3 & 10.8 & 7.7 & 10.9 & 9.5 & 14.0 & 19.2 & 20.3 & 26.3 \\
LT & 216.2 & 24.5 & 24.9 & 21.9 & 20.7 & 22.1 & 22.3 & 20.9 & 23.9 & 23.0 & 24.6 & 23.2 \\
LU & 36.1 & 21.9 & 22.8 & 19.9 & 18.0 & 20.3 & 19.2 & 18.9 & 21.5 & 23.2 & 23.4 & 25.5 \\
LV & 557.7 & 23.9 & 24.0 & 21.5 & 20.5 & 21.4 & 21.6 & 20.2 & 22.8 & 22.2 & 23.8 & 22.1 \\
NL & 41.8 & 26.0 & 28.2 & 26.2 & 23.3 & 76.6 & 27.1 & 26.3 & 29.3 & 31.5 & 31.7 & 111.3 \\
NR & 21.8 & 20.6 & 20.6 & 20.6 & 20.6 & 20.6 & 20.6 & 20.6 & 20.6 & 20.6 & 20.6 & 20.6 \\
PL & 26.8 & 23.6 & 26.4 & 23.0 & 21.6 & 24.9 & 24.0 & 23.3 & 26.2 & 24.2 & 24.9 & 25.6 \\
PT & 22.2 & 18.7 & 16.6 & 15.3 & 12.7 & 11.6 & 13.1 & 12.5 & 15.5 & 18.9 & 20.8 & 24.5 \\
RO & 630.8 & 22.3 & 22.6 & 20.5 & 19.9 & 20.7 & 21.9 & 21.2 & 23.0 & 24.6 & 24.9 & 643.0 \\
SE & 29.4 & 21.0 & 20.9 & 20.3 & 19.7 & 19.3 & 19.2 & 18.2 & 19.3 & 19.5 & 19.9 & 18.1 \\
SI & 22.0 & 19.7 & 18.4 & 16.5 & 15.2 & 15.4 & 15.8 & 15.3 & 17.9 & 21.3 & 21.7 & 25.0 \\
SK & 478.2 & 26.9 & 27.4 & 21.5 & 20.3 & 23.1 & 23.2 & 21.7 & 25.2 & 26.3 & 27.7 & 414.9 \\
UK & 68.3 & 28.7 & 29.2 & 24.6 & 22.0 & 25.5 & 22.1 & 20.0 & 24.8 & 25.1 & 35.2 & 106.4 \\
\hline & & & & & & & & & & & &
\end{tabular}

As a consequence of the situation shown in Figure 9, i.e., high demand and low solar radiation, we observe that higher prices are found in the colder months of the year. This circumstance is specially relevant in countries with low renewable sources and/or poor interconnections with other countries. To look more in the detail, Table 9 gives the percentiles $0,10,50$, 90 and 100 of the daily day-ahead energy prices per country in 2050. In this table, daily price refers to the average price during the day. 
Table 9: Percentiles $0,10,50,90$ and 100 of the daily day-ahead energy price per country in 2050 (€/MWh).

\begin{tabular}{c|rrrrr}
\hline & \multicolumn{5}{|c}{ Percentile } \\
Country & 0 & 10 & 50 & 90 & 100 \\
\hline AT & 10.70 & 18.21 & 20.80 & 25.64 & 37.30 \\
BE & 10.80 & 19.31 & 31.70 & 32.40 & 223.00 \\
CH & 10.20 & 14.41 & 18.60 & 25.79 & 61.60 \\
CZ & 12.50 & 17.00 & 19.60 & 29.09 & 2904.90 \\
DE & 10.90 & 16.60 & 20.70 & 28.99 & 403.50 \\
DK & 3.70 & 10.51 & 17.65 & 29.69 & 139.30 \\
EE & 11.00 & 18.01 & 21.20 & 26.49 & 13758.70 \\
ES & 7.50 & 10.20 & 16.00 & 23.90 & 35.60 \\
FI & 11.60 & 17.10 & 20.70 & 24.40 & 19116.30 \\
FR & 9.90 & 12.60 & 18.70 & 27.86 & 281.40 \\
HU & 14.40 & 20.00 & 23.90 & 43.80 & 18706.80 \\
IT & 3.80 & 7.20 & 14.55 & 24.59 & 82.90 \\
LT & 9.10 & 18.90 & 22.30 & 29.99 & 2728.40 \\
LU & 10.90 & 16.60 & 20.70 & 28.99 & 403.50 \\
LV & 10.00 & 18.51 & 21.90 & 28.60 & 7770.80 \\
NL & 10.50 & 18.62 & 29.00 & 37.80 & 1559.60 \\
NR & 20.60 & 20.60 & 20.60 & 20.60 & 30.40 \\
PL & 4.30 & 18.31 & 23.20 & 30.59 & 99.10 \\
PT & 5.00 & 10.01 & 15.90 & 23.49 & 35.60 \\
RO & 14.30 & 19.11 & 21.55 & 29.59 & 18706.80 \\
SE & 4.20 & 16.60 & 20.40 & 21.80 & 211.60 \\
SI & 9.40 & 14.01 & 17.85 & 24.29 & 50.10 \\
SK & 14.30 & 19.00 & 23.60 & 36.10 & 13774.80 \\
UK & -11.70 & 13.70 & 29.20 & 33.90 & 1121.00 \\
\hline & & & & &
\end{tabular}

In countries such as Finland, Romania, the Netherlands, Hungary, and the United Kingdom very high prices are registered. These unusual prices reflect the presence of unserved demand, that occurs as follows: 35 hours in Finland, 26 hours in Romania, 6 hours in the Netherlands, 4 hours in Hungary, and 4 hours in the United Kingdom. This analysis shows that, even though the expected hours with unserved demand is not relevant along a year, it has a significant impact on the prices. Another particular phenomenon is found in United Kingdom, where negative prices are found is some hours. This fact is a consequence of the enforcement of the technical constraints of thermal units and the low transmission capacity when operating a renewabledominated power system, which can yield in the spillage of renewable resources.
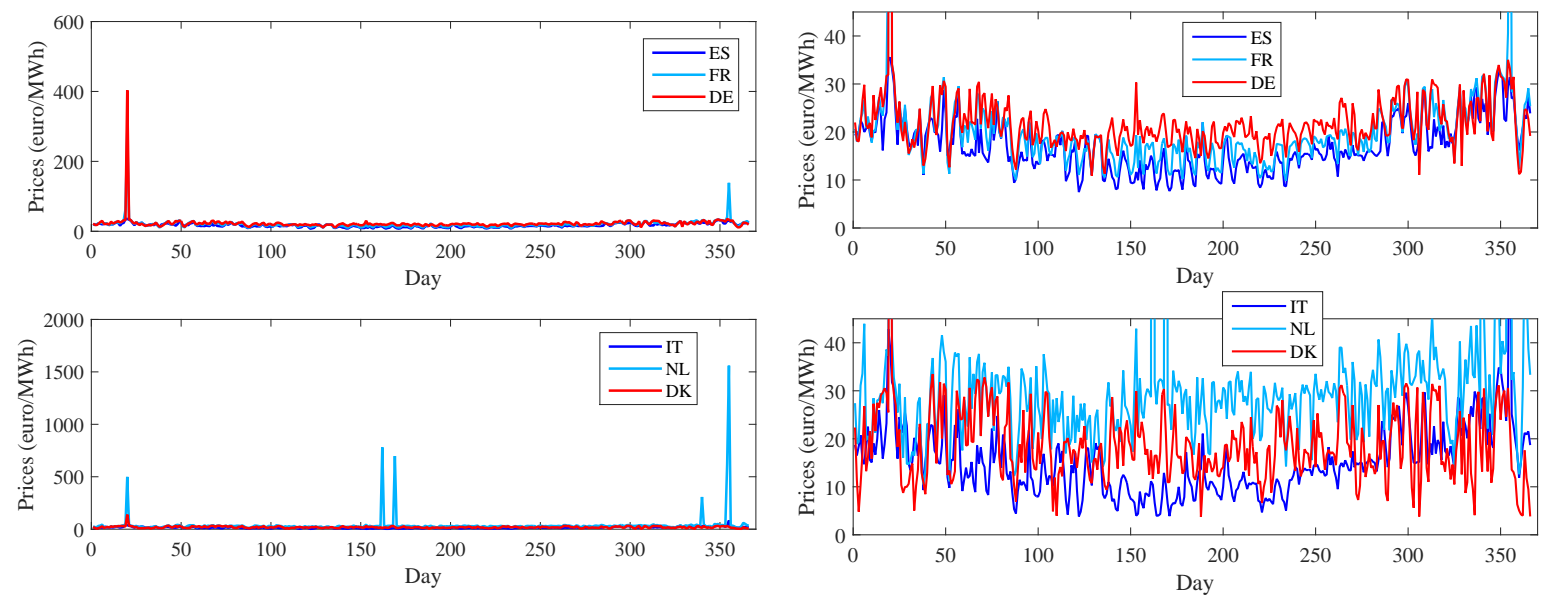

(a) Whole year

(b) Zoom

Figure 12: Daily day-ahead energy price in Spain, France, Germany, Italy, the Netherlands and Denmark in 2050.

Furthermore, Figure 12 depicts the daily day-ahead prices along the year in 6 representative countries, namely Spain, 
France, Germany, Italy, the Netherlands, and Denmark. Figure 12a shows the prices along the whole year, whereas Figure 12b provides a zoom of the previous graph. Figure 12a makes evident the relatively stability of the electricity prices during the year except for particular days in which unserved demand occurs. On the contrary, Figure 12b shows the usual variability in the daily prices, but it also points out the reduction in the daily prices in Spain or in Italy respect to the other analyzed countries.

Finally, Table 10 gives the expected annual cost recovery per technology and the expected revenue adequacy per country, respectively. The cost recovery per technology is computed as the difference between the incomes received from participating in the day-ahead energy and reserve markets and from deploying reserves in the real-time operation, and the costs of providing energy and the annual capital cost (see Morales et al., 2012). The dual variables associated to the day-ahead and real-time balancing constraints, i.e., (24) and (43), are considered as the energy prices. The provision of reserves in the day ahead is assumed to be remunerated "pay-as-bid" to the producers. The revenue adequacy is computed as the difference between the incomes received by the producers and the consumers payments, taking into account the system operator perspective. The formula used to compute the previous results are provided in C.2. Thus, from these results we firstly observed that the expected cost recovery of many technologies and many countries is null, which means that there is no profit for those technologies. On the other side, in those countries with risk of having unserved demand, the high prices in certain hours of the year make the profits of the producers very high (see Finland, for instance). However, in most of the countries the system is revenue adequate.

Table 10: Expected cost recovery per technology and expected revenue adequacy in each country (M€)

\begin{tabular}{c|cccccccccc|r}
\hline Country & Nucl & Coal & CCGT & HRes & HRoR & Wons & Woff & SoPV & SoTH & Biom & Revenue \\
\hline AT & 0.0 & 1.0 & 0.6 & 86.0 & 378.1 & 331.9 & 0.0 & 121.2 & 0.0 & 86.3 & 174.5 \\
BE & 0.0 & 0.0 & 63.6 & 104.1 & 2.3 & 461.8 & 50.9 & 160.2 & 0.0 & 187.5 & -929.6 \\
CH & 377.5 & 0.0 & 0.0 & 122.3 & 9.9 & 0.0 & 0.0 & 0.0 & 0.0 & 17.2 & 139.4 \\
CZ & 779.2 & 266.6 & 200.9 & 182.9 & 36.5 & 51.1 & 0.0 & 74.2 & 0.0 & 130.1 & 89 \\
DE & 0.0 & 977.7 & 274.3 & 277.1 & 314.3 & 2457.7 & 243.6 & 1508.6 & 0.0 & 766.6 & -275.2 \\
DK & 0.0 & 2.5 & 10.6 & 0.0 & 0.0 & 209.8 & 7.8 & 21.4 & 0.0 & 212.7 & 117.6 \\
EE & 0.0 & 20.8 & 406.6 & 0.0 & 3.2 & 0.3 & 0.0 & 0.2 & 0.0 & 357.5 & -300.7 \\
ES & 0.0 & 2.3 & 1.5 & 227.9 & 112.9 & 268.7 & 0.0 & 1206.2 & 507.6 & 159.3 & 0.6 \\
FI & 2400.1 & 433.9 & 2189.9 & 488.8 & 2319.3 & 890.6 & 0.0 & 0.4 & 0.0 & 4084.7 & -4742.0 \\
FR & 2779.9 & 80.9 & 254.8 & 335.6 & 770.3 & 1892.4 & 0.1 & 1032.1 & 0.0 & 355.8 & 740.3 \\
HU & 2131.9 & 5.2 & 94.6 & 27.8 & 14.1 & 206.6 & 0.0 & 48.0 & 0.0 & 514.9 & -3873.5 \\
IT & 0.0 & 30.8 & 13.0 & 131.7 & 862.5 & 559.0 & 0.0 & 936.1 & 88.7 & 388.1 & -166.8 \\
LT & 0.0 & 0.0 & 79.0 & 152.6 & 11.0 & 107.3 & 0.0 & 0.0 & 0.0 & 49.6 & -47.2 \\
LU & 0.0 & 0.0 & 9.4 & 0.0 & 24.4 & 0.0 & 0.0 & 3.5 & 0.0 & 9.5 & -42.7 \\
LV & 0.0 & 0.0 & 317.2 & 0.0 & 132.0 & 26.2 & 0.0 & 0.0 & 0.0 & 81.5 & -119.6 \\
NL & 0.0 & 708.3 & 519.7 & 0.0 & 0.0 & 705.9 & 51.9 & 251.8 & 0.0 & 812.9 & -2002.0 \\
NR & 0.0 & 0.0 & 0.0 & 29.3 & -0.3 & 0.3 & 1.8 & 0.0 & 0.0 & 0.0 & -615.1 \\
PL & 14.2 & 654.5 & 29.8 & 82.4 & 36.6 & 967.0 & 0.0 & 9.5 & 0.0 & 414.5 & -103.5 \\
PT & 0.0 & 0.0 & 0.2 & 27.6 & 138.5 & 354.0 & 0.0 & 94.6 & 79.5 & 40.8 & 208.9 \\
RO & 1230.7 & 763.8 & 1567.6 & 3724.1 & 1358.4 & 554.7 & 0.0 & 294.1 & 0.0 & 382.5 & 367.4 \\
SE & 684.1 & 5.6 & 12.4 & 145.2 & -0.1 & 681.4 & 0.0 & 0.0 & 0.0 & 315.5 & 792.6 \\
SI & 46.6 & 5.7 & 0.4 & 1.9 & 63.6 & 0.0 & 0.0 & 8.9 & 0.0 & 12.3 & -10.3 \\
SK & 978.4 & 490.5 & 425.7 & 0.0 & 628.3 & 17.1 & 0.0 & 70.5 & 0.0 & 423.9 & -433.3 \\
UK & 828.2 & 105.5 & 2077.3 & 0.0 & -0.4 & 921.4 & 414.7 & 431.3 & 0.0 & 4804.1 & -1514.0 \\
\hline EU & 12250.8 & 4555.6 & 8549.2 & 6147.3 & 7215.4 & 11665.5 & 770.7 & 6272.6 & 675.8 & 14607.8 & -12545.3 \\
\hline
\end{tabular}

\section{Conclusions}

In this paper an approach to determine the generating and storage capacity to be built in the European countries up to 2050 and to analyze the resulting power system operation is presented. In particular, the investment decisions to be made in 2017 and 2030 to attain the environmental goals of 2050 are obtained by solving a multi-stage stochastic programming problem where the uncertainty of the demand growth and the investment costs is considered. Then, the operation of the resulting power system for 2050 is analyzed by solving a two-stage stochastic programming problem that represents the clearing of the energy and reserve markets. In this second model, the uncertainty of the wind and solar power availability in the real-time operation is considered by including a set of scenarios. The performed numerical analysis is based on the data provided by ENTSO-E and by the European Commission (2015). The main conclusions obtained from this study are listed bellow.

1. The numerical analysis performed shows that to attain a renewable-dominated European power system may be technically and economically feasible.

2. The expected total generating capacity to be built is $880.65 \mathrm{GW}$, which represents a total investment cost of 1622.5 billion euros. The investments on new energy storage systems will involve a total disbursement of 168 billion euros. 
About $700 \mathrm{GW}$ of the new generating capacity will correspond to solar photovoltaic and onshore wind power, whereas about $6 \mathrm{GW}$ of nuclear power will be built. Most of this new generating capacity will be built after 2030 .

3. Sixteen of the countries will end up with a generating system at least $70 \%$ renewable. In countries like Spain or Italy, most of the new capacity corresponds to solar photovoltaic. In France and Germany, high capacity of solar photovoltaic and onshore wind will be installed. The biomass capacity will increase in most of the countries, while combined-cycle gas turbine units will be also installed in many countries. Moreover, countries with high generating capacity, specially in intermittent power plants, will build high storage capacity.

4. A higher use of the native renewable sources in many countries may lead to a balance between generation and consumption, or even to a change in their import-export balance.

5. Respect to the system operation in 2050 , in the energy mix of $80 \%$ of the countries renewable sources will supply more than $50 \%$ of the electric demand. Higher reserve capacity compared to the current level is needed to counteract the variability of the intermittent renewable production. This outcome is partially affected by the assumption that wind, solar photovoltaic, and storage units can also provide reserve capacity, which reduces the participation of thermal units.

6. The resulting European power system may lead to a reduction of $77 \%$ of the CO2 emissions respect to 1990 in the power sector. Only 6 countries will emit more than $100 \mathrm{gCO} 2 \mathrm{e} / \mathrm{kW}$.

7. It is remarkable that a renewable-dominated power system can lead to the risk of having unserved demand in some countries, but only in very few hours of the year. The high cost penalization given to the unserved demand causes a noticeable effect to the electricity prices. However, the results show that the average daily electricity prices obtained in the day-ahead market are comparatively stable, with values between 15 and $40 € / \mathrm{MWh}$ in most of the countries most of the days.

8. By 2050, the majority of the generating technologies get cost recovery in expectation in most of the countries. However, there are also many technologies with null cost recovery. The whole power system and that of many countries is revenue adequate in expectation.

9. We find that some transmission lines will be congested for a large number of hours of the year. It would be interesting to analyze the impact of having a larger interchange capacity over the investment decisions in generating and storage capacity.

10. Finally, the effect of different degrees of demand side management in the planning and operation of the European power system will be part of our future work.

\section{Acknowledgments}

The work made by Ruth Domínguez and Miguel Carrión has been supported by the Ministry of Economy and Competitiveness of Spain under Project DPI2015-71280-R MINECO/FEDER, UE.

\section{References}

[1] European Commission, 2011. Energy Roadmap 2050. doi:10.2833/10759. Available at: https://ec.europa.eu/ energy/sites/ener/files/documents/2012_energy_roadmap_2050_en_0.pdf

[2] Rasmussen MG, Andresen GB, Greiner M. Storage and balancing synergies in a fully or highly renewable pan-European power system. Energy Policy 2012;51:642-51.

[3] Brancucci Martínez-Anido C, Vandenbergh M, de Vries L, Alecu C, Purvins A, Fulli G, Huld T. Medium-term demand for European cross-border electricity transmission capacity. Energy Policy 2013;61:207-22.

[4] Connolly D, Lünd H, Mathiesen BV. Smart Energy Europe: the technical and economic impact of one potential $100 \%$ renewable energy scenario for the European Union. Renewable and Sustainable Energy Reviews 2016;60:1634-53.

[5] Gils HC, Scholz Y, Pregger T, Luca de Tena D, Heide D. Integrated modelling of variable renewable energy-based power supply in Europe. Energy 2017;123:173-88.

[6] Eriksen EH, Schwenk-Nebbe LJ, Tranberg B, Brown T, Greiner M. Optimal heterogeneity in a simplified highly renewable European electricity system. Energy 2017;133(Suppl. C):913-28.

[7] Schlachtberger DP, Brown T, Schramm S, Greiner M. The benefits of cooperation in a highly renewable European electricity network. Energy 2017;134(Suppl. C):469-81.

[8] Domínguez R, Carrión M, Oggioni G. Toward a fully renewable European electric energy system. Design the electricity market(s) of the future. Chapter of e-book. June 2017. doi:10.2870/420547. 
[9] Schlachtberger DP, Brown T, Schäfer M, Schramm S, Greiner M. Cost optimal scenarios of a future highly renewable European electricity system: Exploring the influence of weather data, cost parameters and policy constraints. Energy 2018;163:100-14.

[10] Brown T, Schlachtberger D, Kies A, Schramm S, Greiner M. Synergies of sector coupling and transmission reinforcement in a cost-optimised, highly renewable European energy system. Energy 2018;160:720-39.

[11] IEA-International Energy Agency, 2016. World Energy Outlook 2016. Available at: https://www . iea.org/weo/

[12] European Commission, 2015. EU Reference Scenario 2016. Energy, transport and GHG emissions. Trends to 2050. Available at: https://ec. europa.eu/energy/node/186

[13] OpenEI, U.S. Department of Energy, National Renewable Energy Laboratory, 2015. Transparent cost database. Available at: https://openei.org/wiki/Transparent_Cost_Database

[14] Kost C, Shammugam S, Julch V, Nguyen HT, Schlegl T. Levelized cost of electricity renewable energy technologies. Fraunhofer Institute for Solar Energy Systems (ISE), 2013.

[15] IRENA-International Renewable Energy Agency, 2017. Electricity storage and renewables: costs and markets to 2030. Available at: http://irena.org/publications/2017/0ct/Electricity-storage-and-renewablescosts-and-markets

[16] Growe-Kuska N, Heitsch H, Romisch W. Scenario reduction and scenario tree construction for power management problems. In Proceedings IEEE Bologna Power Technol. Conf., Bologna, Italy, Jun. 2003.

[17] NREL-National renewable energy laboratory, Western wind and solar integration study, 2010. Available at: https: //goo.gl/NvUBK8.

[18] Gesino AJ. Power Reserve Provision with Wind Farms: Grid Integration of Wind Power. Kassel University press GmbH, 2011.

[19] Lin Y, Ding Y, Song Y, Guo C. A Multi-State Model for Exploiting the Reserve Capability of Wind Power. IEEE Transactions on Power Systems 2018; 33(3), 3358-3372.

[20] Birge JR, Louveaux F. Introduction to Stochastic Programming. Springer-Verlag, New York, NY 1997.

[21] Conejo AJ, Carrión M, Morales JM. Decision Making Under Uncertainty in Electricity Markets. Springer, New York, NY 2010.

[22] Domínguez R, Conejo AJ, Carrión M. Operation of a fully renewable electric energy system with CSP plants. Applied Energy 2014, 119, 417-430.

[23] Rosenthal RE. GAMS, A users guide. Washington, DC: GAMS Development Corp. 2008.

[24] Morales JM, Conejo AJ, Lui K, Zhong J. Pricing electricity in pools with wind producers. IEEE Transactions Power Systems 2012; 27(3), 1366-1376. 


\section{A Notation}

The symbols used to formulate the multi-stage investment model are listed bellow. Indices and sets:
$g$ Index of generating technologies
$i$ Index of characteristic days
$l$ Index of transmission lines
$n$ Index of buses
$o$ Index of hours
$s$ Index of investment scenarios
$t$ Index of decision stages
$\omega$ Index of operating scenarios
$G$ Set of generating units
I Set of characteristic days
$L$ Set of transmission lines
$N$ Set of buses
$O$ Set of hours
$S$ Set of investment scenarios
$T$ Set of decision stages
$\Omega$ Set of operating scenarios

$O(l) / D(l)$ Origin/destination buses of transmission line $l$

$N^{\mathrm{EU}}$ Set of countries belonging to the European Union

$\Omega^{\mathrm{Di}}$ Set of dispatchable generating technologies

$\Omega^{\mathrm{It}}$ Set of intermittent generating technologies

Constants and parameters:

$C_{g t}^{\mathrm{G}}$ Operating cost of generating technology $g$ in stage $t$

$\mathrm{CI}_{n}^{\max }$ Investment budget in node $n$

$C^{\mathrm{US}}$ Cost of the unserved demand

$E_{n}^{\text {ini }}$ Initial energy content in the storage in bus $n$

$E_{n}^{\text {Bmax }}$ Maximum energy capacity that can be built of storage in bus $n$

$F_{\text {gnio }}^{\mathrm{A}}$ Availability factor of generating technology $g$ in bus $n$, day $i$ and hour $o$

$N_{i}^{\mathrm{D}}$ Weight of characteristic day $i$

$P_{g n}^{\mathrm{Imax}}$ Maximum capacity that can be built of generating technology $g$ in bus $n$

$P_{n}^{\mathrm{Bmax}}$ Maximum power capacity that can be built of storage in bus $n$

$P_{g n t}^{\mathrm{Ex}}$ Existing capacity of generating technology $g$ in bus $n$ and stage $t$

$P_{l}^{\max }$ Capacity of transmission line $l$

$R_{g}^{\text {do }}$ Down ramp capacity of generating unit $g$

$R_{g}^{\text {up }}$ Up ramp capacity of generating unit $g$

$\alpha$ Allowance of thermal production

$\eta$ Charging/discharging rate of the storage

$\pi_{s}$ Probability of scenario $s$

Stochastic investment parameters:

$\tilde{c}_{g t s}^{\mathrm{IG}}$ Investment cost of generating technology $g$, in stage $t$ and scenario $s$

$\tilde{c}_{n t s}^{\mathrm{BE}}$ Investment cost of the energy capacity of storage at node $n$, in stage $t$ and scenario $s$

$\tilde{c}_{n t s}^{\mathrm{BP}}$ Investment cost of the power capacity of storage at node $n$, in stage $t$ and scenario $s$ 


\section{Variables:}

$d_{\text {niots }}^{\mathrm{US}}$ Unserved demand in node $n$, day $i$, hour $o$, stage $t$ and scenario $s$

$e_{\text {niots }}$ Energy level in the storage of node $n$, day $i$, hour $o$, stage $t$ and scenario $s$

$e_{n t s}^{\max }$ Energy capacity built of storage in node $n$, stage $t$ and scenario $s$

$p_{n t s}^{\mathrm{B}}$ Power capacity built of storage in node $n$, stage $t$ and scenario $s$

$p_{\text {gnts }}^{\mathrm{I}}$ Capacity built of generating technology $g$, in node $n$, stage $t$ and scenario $s$

$p_{\text {gniots }}^{\mathrm{G}}$ Power output of generating unit $g$, in node $n$, day $i$, hour $o$, stage $t$ and scenario $s$

$p_{\text {niots }}^{\mathrm{Ch}}$ Power charged by the storage in node $n$, day $i$, hour $o$, stage $t$ and scenario $s$

$p_{\text {niots }}^{\text {Ds }}$ Power discharged by the storage in node $n$, day $i$, hour $o$, stage $t$ and scenario $s$

Specific variables of the operating model:

$d_{n i o}^{\mathrm{US}}$ Unserved demand in the DA in node $n$, day $i$ and hour $o$

$d_{\text {niow }}^{\mathrm{US}}$ Unserved demand in the RT in node $n$, day $i$, hour $o$, and $\omega$

$p_{\text {gnio }}^{\mathrm{DA}}$ Power scheduled in the DA by generating technology $g$ of node $n$, in day $i$, and hour $o$

$p_{\text {gniow }}^{\mathrm{G}}$ Power generated in the RT by generating technology $g$ of node $n$, in day $i$, hour $o$, and $\omega$

$p_{\text {nio }}^{\mathrm{BDiDA}}$ Power scheduled in the DA to be discharged by the storage in node $n$, day $i$, and hour $o$

$p_{n i o}^{\mathrm{BChDA}}$ Power scheduled in the DA to be charged by the storage in node $n$, day $i$, and hour $o$

$p_{\text {lio }}^{\mathrm{LDA}}$ Power flow in the DA in line $l$, day $i$ and hour $o$

$p_{\text {liow }}^{\mathrm{LRT}}$ Power flow in the RT in line $l$, day $i$, hour $o$, and scenario $\omega$

$R_{\text {gnio }}^{\mathrm{DG}}$ Down reserve scheduled in the DA by generating technology $g$ of node $n$, in day $i$, and hour $o$

$R_{\text {gnio }}^{\mathrm{UG}} \mathrm{Up}$ reserve scheduled in the DA by generating technology $g$ of node $n$, in day $i$, and hour $o$

$r_{\text {gniow }}^{\mathrm{DG}}$ Down reserve deployed by generating technology $g$ of node $n$, in day $i$, hour $o$, and scenario $\omega$

$r_{\text {gniow }}^{\mathrm{UG}}$ Up reserve deployed by generating technology $g$ of node $n$, in day $i$, hour $o$, and scenario $\omega$

$r_{\text {niow }}^{\mathrm{DB}}$ Down reserve deployed by the storage of node $n$, in day $i$, hour $o$, and scenario $\omega$

$r_{\text {niow }}^{\mathrm{UB}} \mathrm{Up}$ reserve deployed by the storage of node $n$, in day $i$, hour $o$, and scenario $\omega$

$r_{\text {niow }}^{\mathrm{DCh}}$ Down reserve deployed by the storage of node $n$ from the charging, in day $i$, hour $o$, and scenario $\omega$

$r_{\text {niow }}^{\mathrm{DDi}}$ Down reserve deployed by the storage of node $n$ from the discharging, in day $i$, hour $o$, and scenario $\omega$

$r_{\text {niow }}^{\mathrm{UCh}} \mathrm{Up}$ reserve deployed by the storage of node $n$ from the charging, in day $i$, hour $o$, and scenario $\omega$

$r_{\text {niow }}^{\mathrm{UDi}}$ Up reserve deployed by the storage of node $n$ from the discharging, in day $i$, hour $o$, and scenario $\omega$

$\theta_{n i o}^{\mathrm{DA}}$ Voltage angle in the DA in node $n$, day $i$ and hour $o$

$\theta_{\text {niow }}^{\mathrm{RT}}$ Voltage angle in the DA in node $n$, day $i$, hour $o$, and scneario $\omega$

\section{B Formulation of the capacity expansion model}

In this section, we present the formulation of the multi-stage stochastic-programming problem.

$$
\begin{gathered}
\text { Minimize } \sum_{n \in N} \sum_{t \in T} \sum_{s \in S} \pi_{s}\left[\left(\sum_{g \in G} \tilde{c}_{\text {gts }}^{\mathrm{IG}} p_{\text {gnts }}^{\mathrm{I}}+\left(\tilde{c}_{n t s}^{\mathrm{BE}} e_{n t s}^{\max }+\tilde{c}_{n t s}^{\mathrm{BP}} p_{n t s}^{\mathrm{B}}\right)\right)+\right. \\
\left.\sum_{i \in I} \sum_{o \in O} N_{i}^{\mathrm{D}}\left(\sum_{g \in G} C_{\text {gt }}^{\mathrm{G}} p_{\text {gniots }}^{\mathrm{G}}+C^{\mathrm{US}} d_{\text {niots }}^{\mathrm{US}}\right)\right]
\end{gathered}
$$


subject to

$$
\begin{aligned}
& P_{g n}^{\mathrm{Imax}}-\sum_{t=1}^{T} p_{g n t s}^{\mathrm{I}} \geq 0, \forall g, \forall n, \forall s \\
& P_{n}^{\mathrm{Bmax}}-\sum_{t=1}^{T} p_{n t s}^{\mathrm{B}} \geq 0, \forall n, \forall s \\
& E_{n}^{\mathrm{B} \max }-\sum_{t=1}^{T} e_{n t s}^{\max } \geq 0, \forall n, \forall s \\
& \sum_{t \in T}\left(\sum_{g \in G} \tilde{c}_{g t s}^{\mathrm{I}} p_{g n t s}^{\mathrm{I}}+\left(\tilde{c}_{n t s}^{\mathrm{BE}} e_{n t s}^{\max }+\tilde{c}_{n t s}^{\mathrm{BP}} p_{n t s}^{\mathrm{B}}\right)\right) \leq \mathrm{CI}_{n}^{\max }, \forall n, \forall s
\end{aligned}
$$

$p_{g n t s}^{\mathrm{I}}=p_{g n t s^{\prime}}^{\mathrm{I}}, \forall g, \forall n, \forall t, \forall s, s^{\prime}: \Psi_{t}(s)=\Psi_{t}\left(s^{\prime}\right)$

$p_{n t s}^{\mathrm{B}}=p_{n t s^{\prime}}^{\mathrm{B}}, \forall n, \forall t, \forall s, s^{\prime}: \Psi_{t}(s)=\Psi_{t}\left(s^{\prime}\right)$

$e_{n t s}^{\max }=e_{n t s^{\prime}}^{\max }, \forall n, \forall t, \forall s, s^{\prime}: \Psi_{t}(s)=\Psi_{t}\left(s^{\prime}\right)$

$p_{g n t s}^{\mathrm{I}}, e_{n t s}^{\max }, p_{n t s}^{\mathrm{B}} \geq 0, \forall g, \forall n, \forall t, \forall s$

$\sum_{g \in G} p_{\text {gniots }}^{\mathrm{G}}+p_{\text {niots }}^{\mathrm{Ds}}-p_{\text {niots }}^{\mathrm{Ch}}-\sum_{l \mid O(l)=n} p_{\text {liots }}^{\mathrm{L}}+\sum_{l \mid D(l)=n} p_{\text {liots }}^{\mathrm{L}}=(1+r) \tilde{d}_{\text {niots }}-d_{\text {niots }}^{\mathrm{US}}, \forall n, \forall i, \forall o, \forall t, \forall s$

$F_{\text {gnio }}^{\mathrm{A}}\left(P_{\text {gnt }}^{\mathrm{Ex}}+\sum_{u=1}^{t} p_{\text {gnus }}^{\mathrm{I}}\right)-p_{\text {gniots }}^{\mathrm{G}} \geq 0, \forall g, \forall n, \forall i, \forall o, \forall t, \forall s$

$p_{\text {gniots }}^{\mathrm{G}}-p_{\text {gniot }-1, s}^{\mathrm{G}} \geq R_{g}^{\mathrm{up}}, \forall g \in \Omega^{\mathrm{Th}}, \forall n, \forall i, \forall o, \forall t, \forall s$

$p_{\text {gniot-1,s }}^{\mathrm{G}}-p_{\text {gniots }}^{\mathrm{G}} \geq R_{g}^{\mathrm{do}}, \forall g \in \Omega^{\mathrm{Th}}, \forall n, \forall i, \forall o, \forall t, \forall s$

$\sum_{u=1}^{t} p_{\text {nus }}^{\mathrm{B}}-p_{\text {niots }}^{\mathrm{Ds}} \geq 0, \forall n, \forall i, \forall o, \forall t, \forall s$

$\sum_{u=1}^{t} p_{n u s}^{\mathrm{B}}-p_{\text {niots }}^{\mathrm{Ch}} \geq 0, \forall n, \forall i, \forall o, \forall t, \forall s$

$e_{\text {niots }}=e_{\text {nio- } 1, t s}-\eta p_{\text {niots }}^{\mathrm{Ds}}+(1 / \eta) p_{\text {niots }}^{\mathrm{Ch}}, \forall n, \forall i, \forall o, \forall t, \forall s$

$E_{n i}^{\min } \leq e_{n i o t s} \leq \sum_{u=1}^{t} e_{n u s}^{\max }, \forall n, \forall i, \forall o, \forall t, \forall s$

$e_{\text {niots }}=E_{n}^{\mathrm{ini}}, \forall n, \forall i, o=\operatorname{Ini}(\mathrm{o}), \forall t, \forall s$

$e_{\text {niots }} \geq E_{n}^{\mathrm{ini}}, \forall n, \forall i, o=\operatorname{Fin}(\mathrm{o}), \forall t, \forall s$

$0 \leq d_{\text {niots }}^{\mathrm{US}} \leq \tilde{d}_{\text {niots }}, \forall n, \forall i, \forall o, \forall t, \forall s$

$-P_{l}^{\mathrm{Lmax}} \leq p_{\text {liots }}^{\mathrm{L}} \leq P_{l}^{\mathrm{Lmax}}, \forall l, \forall i, \forall o, \forall t, \forall s$

$$
\sum_{g \in \Omega^{\mathrm{Th}}} \sum_{n \in N^{\mathrm{EU}}} \sum_{i \in I} \sum_{o \in O} N_{i}^{\mathrm{D}} p_{\text {gniots }}^{\mathrm{G}} \leq \alpha \sum_{g \in G} \sum_{n \in N^{\mathrm{EU}}} \sum_{i \in I} \sum_{o \in O} N_{i}^{\mathrm{D}} p_{\text {gniots }}^{\mathrm{G}}, t=T, \forall s
$$

The objective function to be minimized is formulated by (1) and comprises: i) the expected investment cost of the new generating capacity and the energy and power capacity of the storages that can be installed in any bus of the system, and ii) the expected cost of operating the system during the year and the possible unserved demand. Note that in this equation we take into account the probability of the scenario and the weight of the characteristic day.

Constraints (2)-(9) refer to the investment decisions, while constraints (10)-(22) define the system operation. Particularly, constraints (2)-(4) limit the generating and storage capacity to be built per unit, bus, stage and scenario, respectively. Constraint (5) enforces an upper bound on the total investment budget in each node and it holds for all scenarios. Constraints (6)-(8) impose the non-anticipativity constraints on the investment decisions and constraint (9) defines the non-negativity of the investment variables.

In addition, constraint (10) enforces the power balance in each node, day, hour, stage, and scenario, considering a reserve margin $r$ as a function of the hourly demand to take into account the possible required reserve capacity. Constraint (11) limits the power output of the generating units considering the availability factor of the resource and the existing and new capacity up 
to stage. Note that $u$ is an auxiliary index of $t$ used to consider the capacity built up to stage $t$. Constraints (12) and (13) impose the ramping capability on the thermal units, namely the nuclear, coal, and CCGT units.

Constraints (14)-(19) refer to the storage units. Constraints (14) and (15) limit the power generated and consumed, respectively, to the power capacity installed of the corresponding battery up to stage $t$. Constraint (16) defines the energy balance in the storages. Constraint (17) establishes the minimum and maximum energy level in the new batteries considering the capacity built up to stage $t$. Constraints (18) and (19) set the initial energy level and the minimum final energy level in the storages in each day, respectively.

Constraint (20) imposes the limit of the involuntary unserved demand to the current demand level, whereas constraints (21) enforce the power flow limits between two buses. Finally, constraint (22) enforces a limit on the power generated by thermal units in the target year.

\section{Formulation of the operating model}

\section{C.1 Model formulation}

The mathematical formulation of the proposed scheduling model is provided bellow. The additional symbols used in this formulation are described in appendix A. Note that in this model we take as input data from the previous model the capacity of the generating $\left(P_{g n}^{\mathrm{Gmax}}\right)$ and storage $\left(P_{n}^{\mathrm{B}}, E_{n}^{\max }\right)$ units, which are the decision variables of the capacity expansion model. Specifically, $P_{g n}^{\mathrm{Gmax}}$ is the expected total capacity (new plus existing) in 2050 of technology $g$ in country $n$ over the set of scenarios. The same reasoning holds for the storage capacity.

Minimize

$$
\begin{aligned}
& \sum_{n \in N} \sum_{i \in I} \sum_{o \in O} N_{i}^{\mathrm{D}}\left[\sum_{g \in G}\left(C_{g}^{\mathrm{G}} p_{\text {gnio }}^{\mathrm{DA}}+C_{g}^{\mathrm{RUG}} R_{\text {gnio }}^{\mathrm{UG}}+C_{g}^{\mathrm{RDG}} R_{\text {gnio }}^{\mathrm{DG}}\right)+C^{\mathrm{B}} p_{\text {nio }}^{\mathrm{BDiDA}}+C^{\mathrm{US}} d_{\text {nio }}^{\mathrm{US}}{ }^{\mathrm{DA}}\right]+ \\
& \sum_{n \in N} \sum_{i \in I} \sum_{o \in O} \sum_{\omega \in \Omega} N_{i}^{\mathrm{D}} \pi_{\omega}\left[\sum_{g \in G}\left(C_{g}^{\mathrm{DUG}} r_{\text {gnio }}^{\mathrm{UG}}-C_{g}^{\mathrm{DDG}} r_{\text {gnio }}^{\mathrm{DG}}\right)+\left(C^{\mathrm{DUB}} r_{\text {nio }}^{\mathrm{UB}}-C^{\mathrm{DDB}} r_{\text {nio }}^{\mathrm{DB}}\right)+C^{\mathrm{US}} d_{\text {nio }}^{\mathrm{US}}\right]
\end{aligned}
$$

subject to

Power balance in the day-ahead market:

$$
\begin{aligned}
& \sum_{g \in G} p_{\text {gnio }}^{\mathrm{DA}}+\left(p_{n i o}^{\mathrm{BDiDA}}-p_{\text {nio }}^{\mathrm{BChDA}}\right)-\left(D_{n i o}^{\mathrm{F}}-d_{n i o}^{\mathrm{US}{ }^{\mathrm{DA}}}\right) \\
& -\sum_{l \mid O(l)=n} p_{\text {lio }}^{\mathrm{LDA}}+\sum_{l \mid D(l)=n} p_{l i o}^{\mathrm{LDA}}=0, \quad \forall n, \forall i, \forall o, \quad\left(\lambda_{n i o}^{\mathrm{DA}}\right)
\end{aligned}
$$

Capacity and ramping limits of generating units day ahead:

$$
\begin{array}{ll}
0 \leq p_{\text {gnio }}^{\mathrm{DA}} \leq F_{\text {gnio }}^{\mathrm{A}} P_{\text {gn }}^{\mathrm{Gmax}}, & \forall g, \forall n, \forall i, \forall o \\
p_{\text {gnio }}^{\mathrm{DA}}-p_{\text {gnio- }}^{\mathrm{DA}} \leq \operatorname{ramp}_{g}^{\mathrm{up}}, & \forall g \in \Omega^{\mathrm{Di}}, \forall n, \forall i, \forall o \\
p_{\text {gnio-1 }}^{\mathrm{DA}}-p_{\text {gnio }}^{\mathrm{DA}} \leq \operatorname{ramp}_{g}^{\mathrm{do}}, & \forall g \in \Omega^{\mathrm{Di}}, \forall n, \forall i, \forall o
\end{array}
$$

Storage constraints day ahead:

$$
\begin{aligned}
& 0 \leq p_{n i o}^{\mathrm{BDiDA}} \leq P_{n}^{\mathrm{B}}, \forall n, \forall i, \forall o \\
& 0 \leq p_{n i o}^{\mathrm{BChDA}} \leq P_{n}^{\mathrm{B}}, \forall n, \forall i, \forall o \\
& e_{n i o}=e_{n i o-1}-\frac{1}{\eta} p_{n i o}^{\mathrm{BDiDA}}+\eta p_{n i o}^{\mathrm{BChDA}}, \forall n, \forall i, \forall o \\
& E_{n}^{\mathrm{min}} \leq e_{n i o} \leq E_{n}^{\mathrm{max}}, \forall n, \forall i, \forall o \\
& e_{n i o} \geq E_{n}^{\mathrm{ini}}, \forall n, \forall i, o=\text { Fin }(\mathrm{o})
\end{aligned}
$$

Transmission line constraints day ahead:

$$
\begin{aligned}
& p_{\text {lio }}^{\mathrm{LDA}}=B_{l}\left(\theta_{O(l), i o}^{\mathrm{DA}}-\theta_{D(l), i o}^{\mathrm{DA}}\right), \quad \forall l, \forall i, \forall o \\
& -P_{l}^{\mathrm{Lmax}} \leq p_{l i o}^{\mathrm{LD}} \leq P_{l}^{\mathrm{Lmax}}, \quad \forall l, \forall i, \forall o \\
& -\pi \leq \theta_{n i o}^{\mathrm{DA}} \leq \pi, \quad \forall n, \forall i, \forall o
\end{aligned}
$$


Unserved demand limit day ahead:

$$
0 \leq d_{n i o}^{\mathrm{US}}{ }^{\mathrm{DA}} \leq D_{n i o}^{\mathrm{F}}, \quad \forall n, \forall i, \forall o
$$

Minimum reserve requirements day ahead:

$$
\begin{aligned}
& \sum_{g \in G} R_{\text {gnio }}^{\mathrm{DG}}+R_{n i o}^{\mathrm{DB}} \geq\left(K^{\mathrm{D}} D_{\text {nio }}^{\mathrm{F}}+K^{\mathrm{It}} \sum_{g \in \Omega^{\mathrm{It}}} F_{\text {gnio }}^{\mathrm{A}} P_{\text {gn }}^{\mathrm{Gmax}}\right), \quad \forall n, \forall i, \forall o \\
& \sum_{g \in G} R_{\text {gnio }}^{\mathrm{UG}}+R_{\text {nio }}^{\mathrm{UB}} \geq\left(K^{\mathrm{D}} D_{\text {nio }}^{\mathrm{F}}+K^{\mathrm{It}} \sum_{g \in \Omega^{\mathrm{It}}} F_{\text {gnio }}^{\mathrm{A}} P_{\text {gn }}^{\mathrm{Gmax}}\right), \quad \forall n, \forall i, \forall o
\end{aligned}
$$

Upper bounds on the scheduled reserve:

$$
\begin{array}{ll}
0 \leq R_{\text {gnio }}^{\mathrm{UG}} \leq R_{\text {gio }}^{\mathrm{GRmax}}, & \forall g, \forall n, \forall i, \forall o \\
0 \leq R_{\text {gnio }}^{\mathrm{DG}} \leq R_{\text {gio }}^{\mathrm{GRmax}}, & \forall g, \forall n, \forall i, \forall o \\
0 \leq R_{\text {nio }}^{\mathrm{UB}} \leq R_{i o}^{\mathrm{BRmax}}, & \forall n, \forall i, \forall o \\
0 \leq R_{\text {nio }}^{\mathrm{DB}} \leq R_{i o}^{\mathrm{BRmax}}, & \forall n, \forall i, \forall o
\end{array}
$$

Power balance real time:

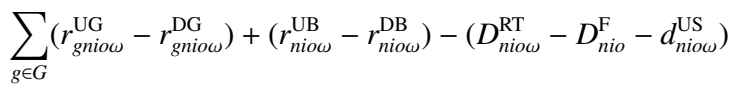

$$
\begin{aligned}
& -\sum_{l \mid O(l)=n}\left(p_{\text {liow }}^{\mathrm{LRT}}-p_{\text {lio }}^{\mathrm{LDA}}\right)+\sum_{l \mid D(l)=n}\left(p_{\text {liow }}^{\mathrm{LRT}}-p_{\text {lio }}^{\mathrm{LDA}}\right)=0, \quad \forall n, \forall i, \forall o, \forall \omega \quad\left(\lambda_{\text {nio }}^{\mathrm{RT}}\right)
\end{aligned}
$$

Capacity and ramping limits of generating units in real time:

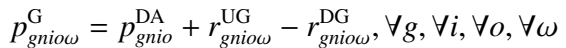

$$
\begin{aligned}
& 0 \leq p_{\text {gnio }}^{\mathrm{G}} \leq F_{\text {gnio }}^{\mathrm{Ar}} P_{\text {gn }}^{\mathrm{Gmax}}, \quad \forall g, \forall n, \forall i, \forall o, \forall \omega
\end{aligned}
$$

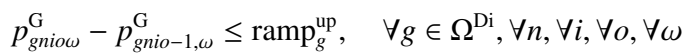

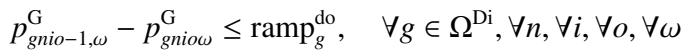

Upper bounds on reserve deployment in each scenario:

$$
\begin{aligned}
& 0 \leq r_{\text {gniow }}^{\mathrm{UG}} \leq R_{\text {gnio }}^{\mathrm{UG}}, \quad \forall g, \forall n, \forall i, \forall o, \forall \omega \\
& 0 \leq r_{\text {gnio }}^{\mathrm{DG}} \leq R_{\text {gnio }}^{\mathrm{DG}}, \quad \forall g \in \Omega^{\mathrm{Di}}, \forall n, \forall i, \forall o, \forall \omega
\end{aligned}
$$

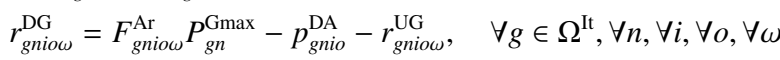

$$
\begin{aligned}
& 0 \leq r_{\text {niow }}^{\mathrm{UB}} \leq R_{\text {nio }}^{\mathrm{UB}}, \quad \forall n, \forall i, \forall o, \forall \omega \\
& 0 \leq r_{\text {nio }}^{\mathrm{DB}} \leq R_{\text {nio }}^{\mathrm{DB}}, \quad \forall n, \forall i, \forall o, \forall \omega
\end{aligned}
$$

Storage operation in real time:

$$
\begin{aligned}
& r_{\text {niow }}^{\mathrm{UB}}=r_{\text {niow }}^{\mathrm{UCh}}+r_{\text {niow }}^{\mathrm{UDi}}, \forall n, \forall i, \forall o, \forall \omega \\
& 0 \leq r_{\text {nio }}^{\mathrm{UCh}} \leq p_{\text {nio }}^{\mathrm{BChDA}}, \forall n, \forall i, \forall o, \forall \omega \\
& 0 \leq r_{\text {nio }}^{\mathrm{UDi}} \leq P_{n}^{\mathrm{B}}-p_{\text {nio }}^{\mathrm{BDiDA}}, \forall n, \forall i, \forall o, \forall \omega \\
& r_{\text {niow }}^{\mathrm{DB}}=r_{\text {niow }}^{\mathrm{DCh}}+r_{\text {niow }}^{\mathrm{DDi}}, \forall n, \forall i, \forall o, \forall \omega \\
& 0 \leq r_{\text {nio }}^{\mathrm{DCh}} \leq P_{n}^{\mathrm{B}}-p_{\text {nio }}^{\mathrm{BChDA}}, \forall n, \forall i, \forall o, \forall \omega \\
& 0 \leq r_{\text {nio }}^{\mathrm{DDi}} \leq p_{\text {nio }}^{\mathrm{BDiDA}}, \forall n, \forall i, \forall o, \forall \omega
\end{aligned}
$$

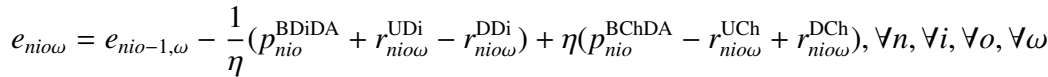

$$
\begin{aligned}
& E_{n}^{\min } \leq e_{\text {niow }} \leq E_{n}^{\max }, \forall n, \forall i, \forall o, \forall \omega \\
& e_{\text {niow }} \geq E_{n}^{\mathrm{ini}}, \forall n, \forall i, o=\operatorname{Fin}(\mathrm{o}), \forall \omega
\end{aligned}
$$


Transmission line constraints:

$$
\begin{aligned}
& p_{\text {liow }}^{\mathrm{LRT}}=B_{l}\left(\theta_{O(l) i o \omega}^{\mathrm{RT}}-\theta_{D(l) i o \omega}^{\mathrm{RT}}\right), \quad \forall l, \forall i, \forall o, \forall \omega \\
& -P_{l}^{\mathrm{Lmax}} \leq p_{\text {liow }}^{\mathrm{LRT}} \leq P_{l}^{\mathrm{Lmax}}, \quad \forall l, \forall i, \forall o, \forall \omega \\
& -\pi \leq \theta_{\text {nio }}^{\mathrm{RT}} \leq \pi, \quad \forall n, \forall i, \forall o, \forall \omega
\end{aligned}
$$

Limit on the unserved demand:

$$
0 \leq d_{\text {niow }}^{\mathrm{US}} \leq D_{\text {niow }}^{\mathrm{RT}}, \quad \forall n, \forall i, \forall o, \forall \omega
$$

The objective function (23) comprises the cost of scheduling energy and reserve capacity in the day ahead and the deployment of the reserves in the real-time operation. Specifically, the terms in the first line of (23) refer to the day-ahead market and represent the cost of the energy and up and down reserve capacity scheduled by the generating units, the cost of the discharged energy scheduled by storage units, and the possible unserved demand, respectively. The terms in the second line of (23) represent the expected cost of counteracting the deviations found in the real-time operation, i.e., the cost of the up and down reserves deployed by generating units and storages, and the possible unserved demand, respectively. We include a cost on the discharging and the reserve deployment of the storages to take into account their degradation costs, even though this cost is significantly lower than the operating cost of the generating units.

The problem is subject to two sets: constraints (24)-(42) describe the day-ahead market and constraints (43)-(65) refer to the real-time operation. Constraint (24) imposes the power balance in the day-ahead market. Constraints (25)-(27) set the power output and ramping limits of the generating units. Parameter $F_{g n i o}^{\mathrm{A}}$ corresponds to the availability factor of generating unit $g$ of bus $n$ in day $i$ and hour $o$ predicted in the day ahead. This value will be variable for intermittent units but constant for dispatchable units. Constraints (28)-(32) characterize the operation of storages in the day-ahead market. Constraints (28) and (29) limit the charged and discharged power. Constraint (30) defines the energy balance in the storage as the energy content in the previous hour minus the discharged power plus the charged power considering the charge rate of the storage. Constraints (31) enforce the minimum and maximum energy content in the storage. Constraint (32) imposes that a minimum energy level in the storage in the end of the day. Constraints (33)-(35) establish the transmission capacity limits among the buses, while constraint (36) limit the unserved demand to the predicted demand consumed in the day-ahead market.

Constraints (37) and (38) impose minimum down and up reserve capacities in the day-ahead market as a function of the predicted demand and intermittent available power in each node, day, and hour. Factors $K^{\mathrm{D}}$ and $K^{\mathrm{It}}$ define the considered margin. Constraints (39)-(42) limit the up and down reserve capacities that can be provided by generating units and storages, respectively.

Constraint (43) imposes the power balance in the real-time operation considering the reserves deployed to counteract the deviations found between the predicted demand and intermittent available power and their actual realization in each real-time scenario. Constraints (44)-(47) define the power output in the real time and the capacity and ramping limits of the generating units. Parameter $F_{\text {gniow }}^{\mathrm{A}}$ represents the availability factor of the generating unit in each scenario. Constraints (48)-(52) limit the up and down deployed reserves for generating units and storages, respectively. For intermittent units we specify the value of the down deployed reserve through (50) to include as down reserve the power spillage.

Constraints (53)-(61) describe the operation of the storages in the real time. Constraints (53)-(55) define and limit the up deployed reserve considering the up reserve provided from the charging and discharging modes of the storage. Similarly, constraints (56)-(58) limit the down deployed reserve. Constraint (59) establishes the energy balance in the real-time operation considering the scheduled charged and discharged power and the deployed reserves. Constraint (60) enforces the minimum and maximum energy capacity limits and constraint (61) imposes the minimum energy level in the storage in the end of the day.

Finally, constraints (62)-(64) set the capacity limit of the transmission network and constraint (65) limit the unserved demand in the real-time operation.

\section{C.2 Economic definitions}

The cost recovery $(\mathrm{CR})$ attained per technology in each country in expectation is computed as follows:

$$
\begin{aligned}
\mathrm{CR}_{g n}= & \sum_{i \in I} \sum_{o \in O} N_{i}^{\mathrm{D}}\left[\lambda_{\text {nio }}^{\mathrm{DA}} p_{\text {gnio }}^{\mathrm{DA}}+C_{g}^{\mathrm{RUG}} R_{\text {gnio }}^{\mathrm{UG}}+C_{g}^{\mathrm{RDG}} R_{\text {gnio }}^{\mathrm{DG}}+\sum_{\omega \in \Omega} \pi_{\omega}\left(\lambda_{\text {nio }}^{\mathrm{RT}}\left(p_{\text {gnio }}^{\mathrm{RT}}-p_{\text {gnio }}^{\mathrm{DA}}\right)\right)\right] \\
& -\sum_{i \in I} \sum_{o \in O} N_{i}^{\mathrm{D}} \sum_{\omega \in \Omega} \pi_{\omega} C_{g}^{\mathrm{G}} p_{\text {gnio }}^{\mathrm{RT}}-C_{g}^{\mathrm{AnnInv}}, \forall g, \forall n
\end{aligned}
$$

being $C_{g}^{\text {AnnInv }}$ the annualized investment cost of technology $g$. 
The revenue adequacy (RA) per country in expectation is computed as follows:

$$
\begin{aligned}
\mathrm{RA}_{n}= & \sum_{g \in G} \sum_{i \in I} \sum_{o \in O} N_{i}^{\mathrm{D}}\left[\lambda_{\text {nio }}^{\mathrm{DA}} p_{\text {gnio }}^{\mathrm{DA}}+C_{g}^{\mathrm{RUG}} R_{\text {gnio }}^{\mathrm{UG}}+C_{g}^{\mathrm{RDG}} R_{\text {gnio }}^{\mathrm{DG}}+\sum_{\omega \in \Omega} \pi_{\omega}\left(\lambda_{\text {nio }}^{\mathrm{RT}}\left(p_{\text {gnio }}^{\mathrm{RT}}-p_{\text {gnio }}^{\mathrm{DA}}\right)\right)\right] \\
& -\sum_{i \in I} \sum_{o \in O} N_{i}^{\mathrm{D}}\left[\lambda_{\text {nio }}^{\mathrm{DA}}\left(D_{\text {nio }}^{\mathrm{F}}-d_{\text {nio }}^{\mathrm{US}}\right)+C^{\mathrm{US}}\left(d_{\text {nio }}^{\mathrm{US}}-\sum_{\omega i n \Omega} \pi_{\omega} d_{\text {nio }}^{\mathrm{DA}}\right)\right], \forall n
\end{aligned}
$$

